\title{
Nonequilibrium Plasma Aerodynamics
}

\author{
Andrey Starikovskiy ${ }^{1}$ and Nickolay Aleksandrov² \\ 1 Princeton University \\ ${ }^{2}$ Moscow Institute of Physics and Technology \\ 1 USA \\ ${ }^{2}$ Russia
}

\section{Introduction}

Currently, the problem of flow active control by low-temperature plasma is considered to be one of the most booming realms of aerodynamics [Bletzinger et al, 2005, Moreau, 2007]. One of the main practical advantages of plasma-assisted flow control is its zero reaction time. This, in principle, provides control over a wide range of frequencies as well as covering a wide range of processes beginning from stationary to separated and turbulent flows. Two other important advantages of plasma systems are their low weights and sizes. If combined with relatively low energy consumption, the features allow the possibility of principally developing new systems of flight control at high velocities [Nikipelov, 2009].

Promising applications of plasma systems to control flow involve the management of laminar-to-turbulent transition in the boundary layer, the management of flow detachment or attachment to the surface, and the resultant management of lift and drag force of an airfoil. This also provides management of noise and vibrations, and control of shock wave patterns as well as their interactions with the boundary layer.

One of the first attempts of flow control using nonequilibrium plasma was performed more than 40 years ago [Mhitaryan et al, 1964]. The authors investigated the flow separation control by surface dielectric barrier discharge with sinusoidal high-voltage power supply in the frequency range $f=50-570 \mathrm{~Hz}$. Figure 1 shows the scheme of the experimental installation [Mhitaryan et al, 1964].

The authors [Mhitaryan et al, 1961, 1964] demonstrated up to 30\% drag force decrease and $40 \%$ lift force increase for airfoil with $460 \mathrm{~mm}$ chord length $\left(\mathrm{AoA}=8^{0}\right)$, thickness of $13 \%$ and flap length $30 \%\left(\mathrm{AoA}=43^{\circ}\right)$ of the chord in velocity range from 8.75 to $20.4 \mathrm{~m} / \mathrm{s}$. They demonstrate that the parameter $c_{\mu_{e}}=\frac{2 P_{a} \cdot l}{\rho V^{2} \cdot b \cdot U \cdot S \cdot \cos \varphi}$ (discharge power density) controls the discharge efficiency. Here $P_{a}$ is active power of the discharge, $l$ - plasma layer length, $V$ - free stream velocity, $\rho$ - gas density, $b$ - ions mobility, $U$ - discharge voltage, $S$ airfoil surface, $\varphi$ - phase shift. The authors made a conclusion that the actuator affects the flow through ionic wind mechanism when induced velocity was in the order of $20-25 \%$ from the velocity of free stream. 

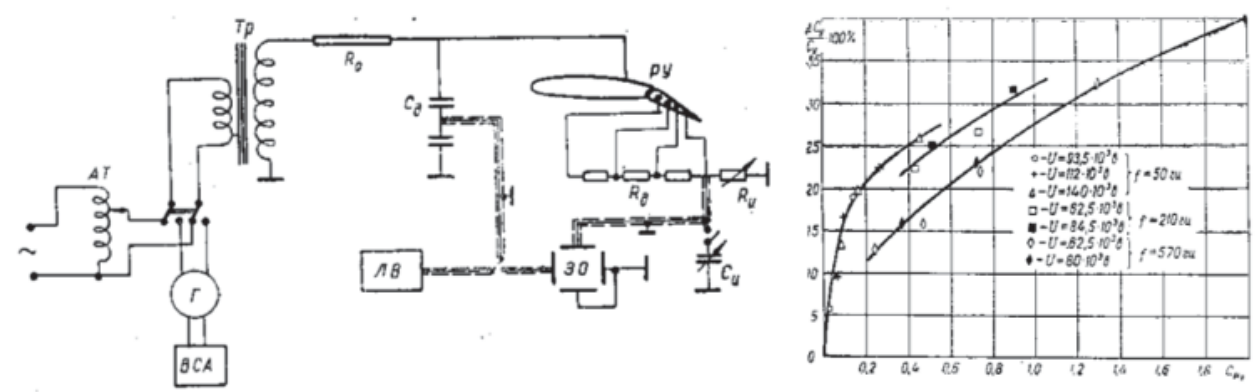

Fig. 1. a) Scheme of the experimental installation [Mhitaryan et al, 1964].

$\mathrm{Tp}$ - high-voltage transformer; $\mathrm{R}_{0}$ - limiting resistor; $\mathrm{C}_{\mathrm{d}}$ - capacitive voltage attenuator;

$R_{d}$ - reactive attenuator; PY - plasma generation region; $R_{u}$ - resistor and $C_{u}$ - capacitor for electrical measurements; $3 \mathrm{O}$ - oscillograph; $\Pi \mathrm{\Pi}$ - voltmeter; $\Gamma$ - generator;

BCA - reference DC power supply; AT - autotransformer.

b) - relative lift force increase.

The thermal management constraints mean that hypersonic flight at Mach numbers greater than 10 can be achieved only at very high altitudes. That is why the plasma mechanisms of external flow modification, shock wave reconfiguration and drag force reduction were considered as an important alternative to traditional solutions for thermal management [Bletzinger et al, 2005].

The paper [Klimov et al, 1982] was one of the first articles devoted to the impact of plasma effects on shock wave propagation. The authors observed an increasing velocity of shock waves propagating in the gas discharge tube with simultaneous amplitude decrease (Figure 2). They compared the observed increase of shock wave velocity with the calculated values corresponding to the discharge heat release. The difference obtained $(1200-1300 \mathrm{~m} / \mathrm{s}$ instead of $900 \mathrm{~m} / \mathrm{s}$ ) was explained by a possible release of vibrational energy, quenching of electronically excited states and double layer formation in front of the SW.
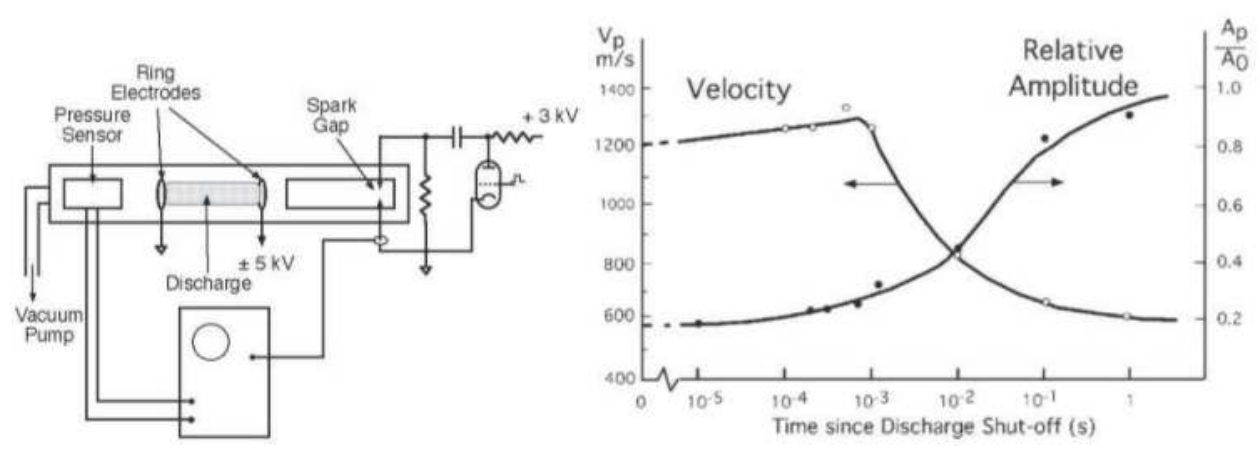

Fig. 2. a) Schematic of experiment of [Klimov et al, 1982]; b) Dependence of the velocity and relative amplitude of the shock wave in the decaying plasma on the delay time since switchoff of the discharge. $A_{\mathrm{p}}$ and $A_{0}$ are the amplitudes of the shock waves in air and in the plasma, respectively. 
A number of imaginative schemes were proposed for modifying and controlling the flow around a hypersonic vehicle. These schemes included novel approaches for plasma generation, magnetohydrodynamic (MHD) flow control and power generation and new hot gas counter-flows and other purely thermal approaches [Bletzinger et al, 2005]. The first of these highly innovative concepts of the aircraft called AJAX (Ayaks) was developed by Vladimir Freishtadt in the late 1980s. The project of this new hypersonic, air-breathing aircraft is currently under development by the Leninetz Holding Company in St. Petersburg, Russia [Gurijanov\&Harsha 1996]. Schematics of AJAX concept is shown in Figure 3.

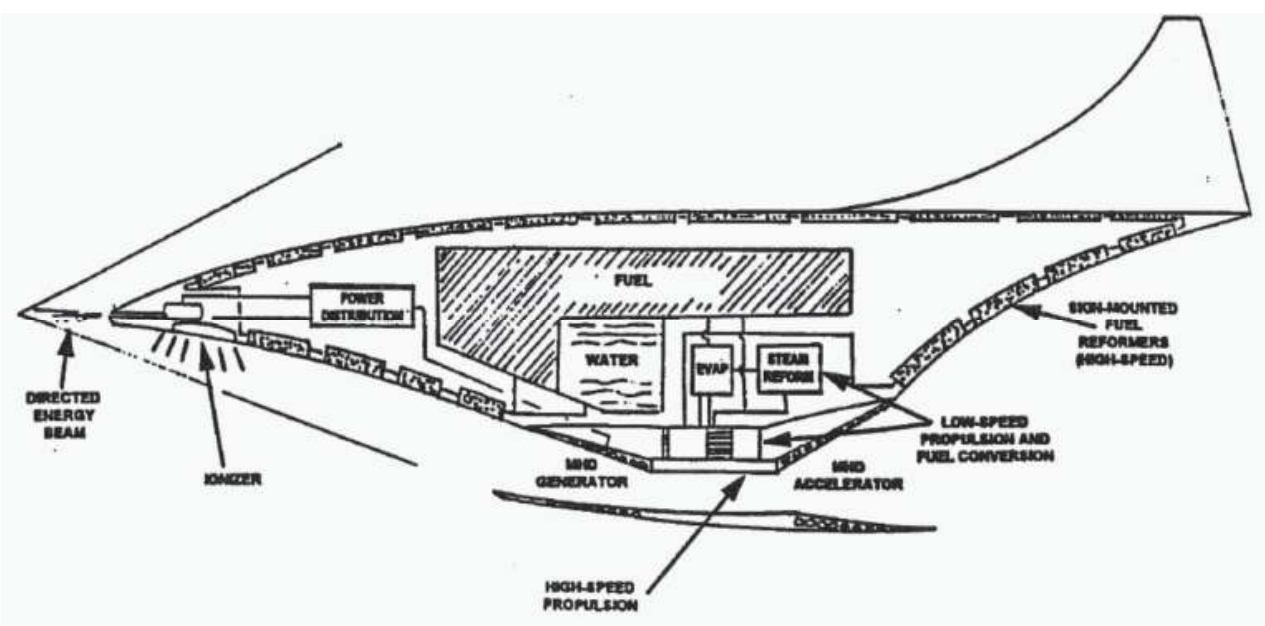

Fig. 3. AJAX concept [Gurijanov\&Harsha 1996].

The AJAX was projected to employ a novel engine that uses some form of MHD generator to collect and slow down highly ionized and rarefied air. The air is mixed with fuel into the mixture that burns in the plasma-stabilized combustor, while the electricity produced by the inlet's MHD generator is used in the magneto-plasmadynamic thruster to provide additional thrust. The plasma funnel developed over the air inlet from the magnetohydrodynamics forces greatly increases the ability of the engine to collect air, increasing the effective diameter of the air inlet.

Further increase of interest to plasma assisted flow control took place in 1993 when Roth and co-workers re-invented surface discharge application for boundary layer separation control. The paper [Roth, 2003] demonstrates the AC dielectric surface discharge ability to suppress the flow separation in low-speed regimes. Figure 4 demonstrates the reattachment of an air flow at $\mathrm{AoA}=8^{0}$ and free stream velocity of $2.85 \mathrm{~m} / \mathrm{s}$.

Another exciting experiment was presented by Bedin and Mishin in [Bedin\&Mishin, 1995]. Ballistic range tests were conducted to measure the drag of a sphere flying through gas discharge plasmas. Experiments were conducted using $15 \mathrm{~mm}$ polyethylene spheres fired at speeds between 200 and $1350 \mathrm{~ms}^{-1}$ in air at 15 Torr. A RF generator operating at $440 \mathrm{kHz}$ was used to produce weak plasma $\left(a \leq 10^{-6}\right)$ over a length of $3 \mathrm{~m}$. The gas temperature in the discharge was approximately $1140 \mathrm{~K}$ and the electron temperature was estimated as $\mathrm{T}_{\mathrm{e}} \sim 2-4 \mathrm{eV}$. The authors report anomalous shock standoff distances for the spheres within the discharge zone at distances far from the thermal nonuniformities near the entrance to 
the plasma. Time-of-flight measurements were made to determine the drag coefficient of the sphere with an accuracy of $1 \%$ in ambient air and $3 \%$ in plasma. The resulting drag coefficient (CD) measurements, shown in Figure 5, indicate a substantial decrease in the drag coefficient at subsonic speeds, with a small increase at supersonic speeds. The decrease in $C D$ observed at subsonic speeds in the presence of the plasma is inconsistent with that expected with the higher temperatures and lower Reynolds number obtained in these experiments. The authors indicated that the observed effects were due to a higher velocity with disturbances transferred throughout the flowfield in the presence of plasma.
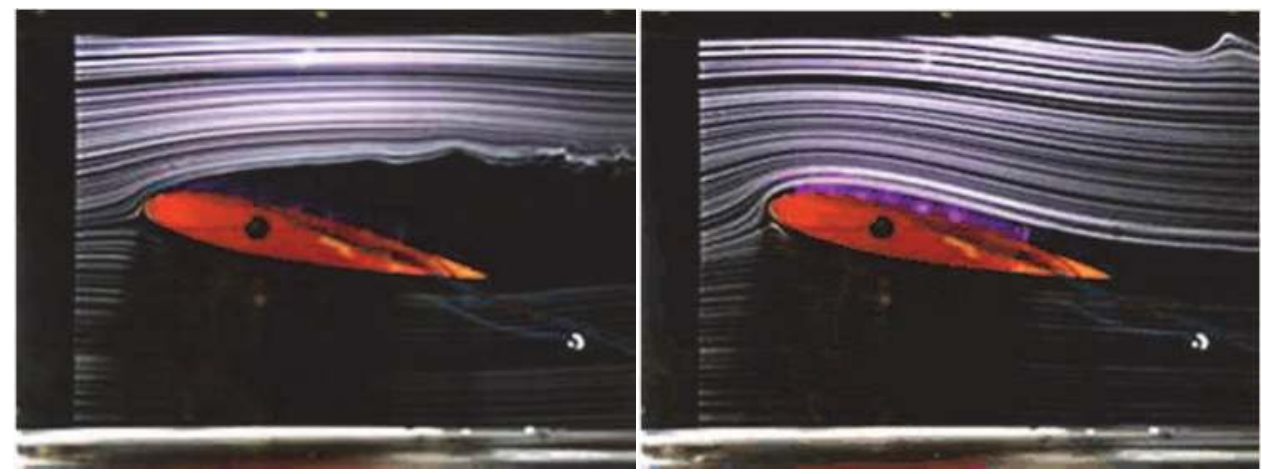

Fig. 4. Low-speed flow separation control by surface dielectric barrier discharge plasma. NACA-0015 airfoil, V = $2.85 \mathrm{~m} / \mathrm{sec}, \mathrm{AoA}=8^{0}$ [Roth, 2003].

Flow control opportunities by plasma could be summarized into two groups: 1) main flow control, including shock wave configuration in supersonic and hypersonic regimes; 2) boundary layer control.

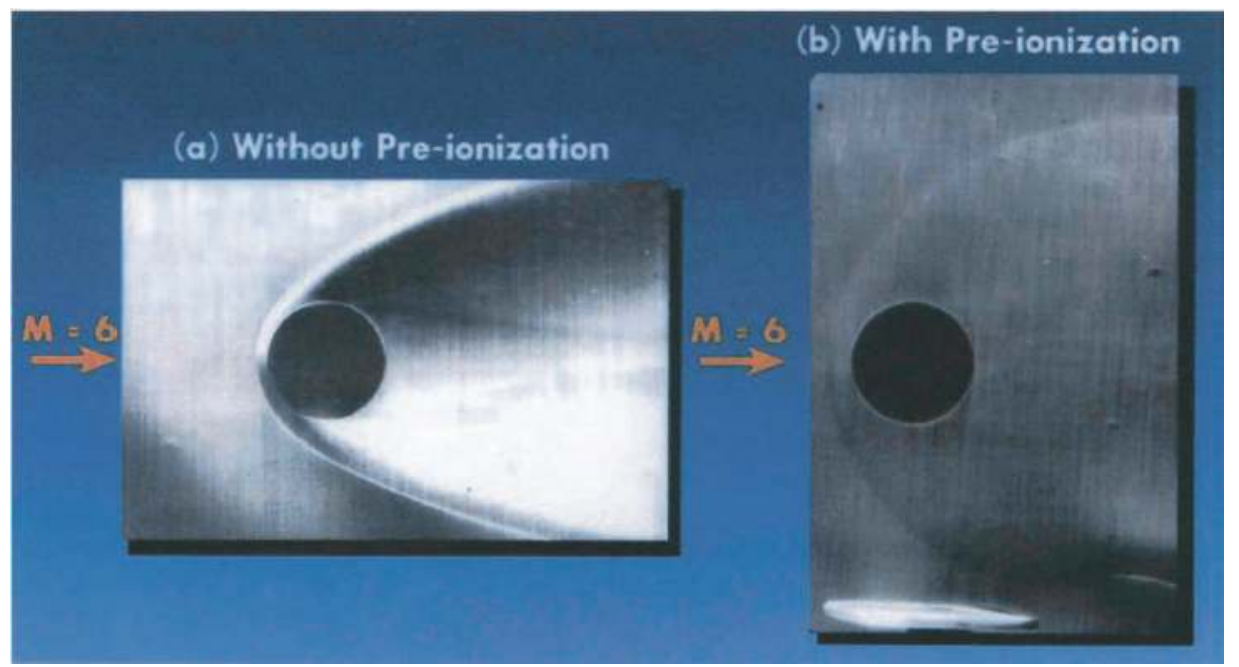

Fig. 5. Schlieren photographs of flow around sphere: (a) flight through air without discharge and $(b)$ flight through the positive column of a glow discharge in air [Bedin\&Mishin, 1995]. 
Main flow control includes shock wave pattern control; aerodynamic breaking; drag reduction; heat mitigation; flow vectorization, acceleration and deceleration; MHD power extraction and breaking.

Boundary layer control could be subdivided into laminar-turbulent transition control; boundary layer separation control; lift and drag force control; acoustic noise control; mixing enhancement.

Nonequilibrium plasma also may be very efficient in ignition and flame stabilization control; engine performance enhancement, including possibility of fast initiation of detonation waves and transition from Braiton $(P=$ const $)$ to more efficient Humphrey $(V=$ const $)$ thermodynamic cycle [Starikovskii, 2005; Starikovskii et al, 2008].

Three different physical mechanisms control the efficiency of plasma aerodynamics. There are: 1) gas heating; 2) electrostatic momentum transfer to the gas; 3) magneto-hydrodynamic effects, including MHD flow acceleration and on-board electricity generation using gas flow kinetic energy. Sometimes it is necessary to take into account gas dissociation and change of average molecular weight of the gas, but strong dissociation or ionization of the gas require huge amount of the energy. That is why for aerospace applications we generally trying to keep the gas excitation on the minimal possible level, which decreases the role of variation of gas composition in the discharge.

Increased interest to plasma assisted flow caused an increased publications flux. There were a lot of impressive demonstrations of plasma-assisted flow control during last 10 years. A lot of them were summarized in several topical reviews published recently. For example, possibilities of supersonic flow control (including shock wave attenuation and shock configuration change) by plasma were discussed in [Bletzinger et al, 2005]. Drag reduction at high speed by energy deposition was discussed in paper [Knight, 2008]. Boundary layer separation control by non-equilibrium non-thermal plasma was reviewed in [Zouzou et al, 2006] and [Corke et al, 2010]. In addition, the recent review [Miles, 2011] includes a lot of results of all mechanisms (thermal, electrostatic and MHD) applications for flow control for subsonic and supersonic regimes.

That is why in our current review we will only briefly mention the most important results in plasma assisted aerodynamics and will focus on the physical mechanisms which limit or promote our abilities to control the flow field by plasma.

\section{Supersonic flow and shock waves control}

On the whole, two approaches can be distinguished to explain the nature of the supersonic plasma-flow interaction. The former describes the process in terms of the thermal mechanism of interaction connected with the energy release in the discharge. Meanwhile, the latter considers the momentum transfer from the electric field to gas flow to be the main mechanism of the process, this is a pure plasma mechanism due to charged components; it is caused by uncompensated spatial charge and is related to volume forces.

The above-mentioned paper [Klimov et al, 1982] demonstrated an increasing velocity of shock waves propagating in the gas discharge tube with simultaneous amplitude decrease. The authors compared the observed increase of shock wave velocity with the calculated values corresponding to the discharge heat release. The difference obtained (1200-1300 m/s instead of $900 \mathrm{~m} / \mathrm{s}$ ) was explained by a possible release of vibrational energy, quenching of electronically excited states and double layer formation in front of the SW. However, later works questioned such interpretation [Meyer et al, 2003; Miles et al, 2001]. Gas heating in discharge was considered the main effect responsible for the changes of flow parameters (Figure 6). 

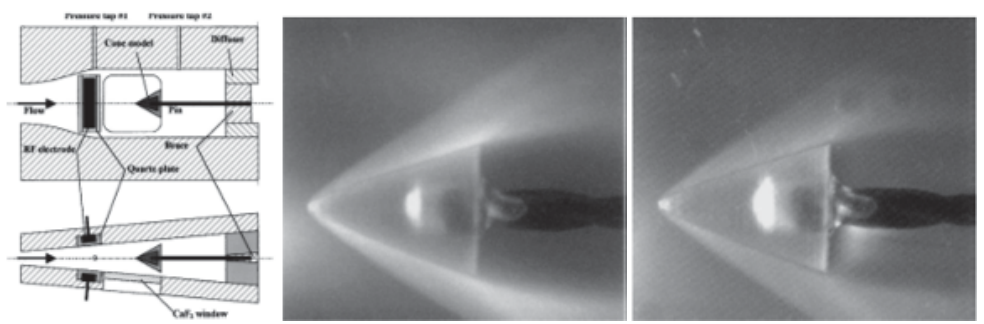

Fig. 6. a) Schematic of the supersonic RF discharge/test section: side view and top view. b-c) Photographs of the supersonic flow over a cone visualized by plasma generated by DC and RF discharges in a $30 \% \mathrm{~N}_{2}-70 \%$ He flow at $P_{0}=250$ Torr: c) only $175 \mathrm{~W}$ DC discharge is on and d) both $175 \mathrm{~W}$ DC and $250 \mathrm{~W}$ RF discharge are on [Meyer et al, 2003].

In the paper [Meyer et al, 2003] an experimental study of shock modification in an $M=2.5$ supersonic flow of nonequilibrium plasma over a cone is discussed. The experiments are conducted in a nonequilibrium plasma supersonic wind tunnel using a supersonic plasma flow over a quasi-two-dimensional wedge. The experiments showed that an oblique shock can be considerably weakened by transverse RF discharge plasma. The observed shock weakening has been found consistent with a temperature rise in the boundary layers heated by the discharge.

Spark-generated shock waves were studied in [Miles et al, 2001] in glow discharges in argon and argon-nitrogen mixtures. A direct proof of the thermal mechanism of shock waveplasma interaction was obtained for pulsed discharges. With a sub-millisecond delay between starting the discharge and shock launch, plasma parameters reach their steadystate values, but because of low discharge power the temperature increase was low during several milliseconds. It was shown that laser schlieren signals are virtually identical to those without the discharge, differing dramatically from the signals in discharges with fully established temperature profiles (Figure 7).
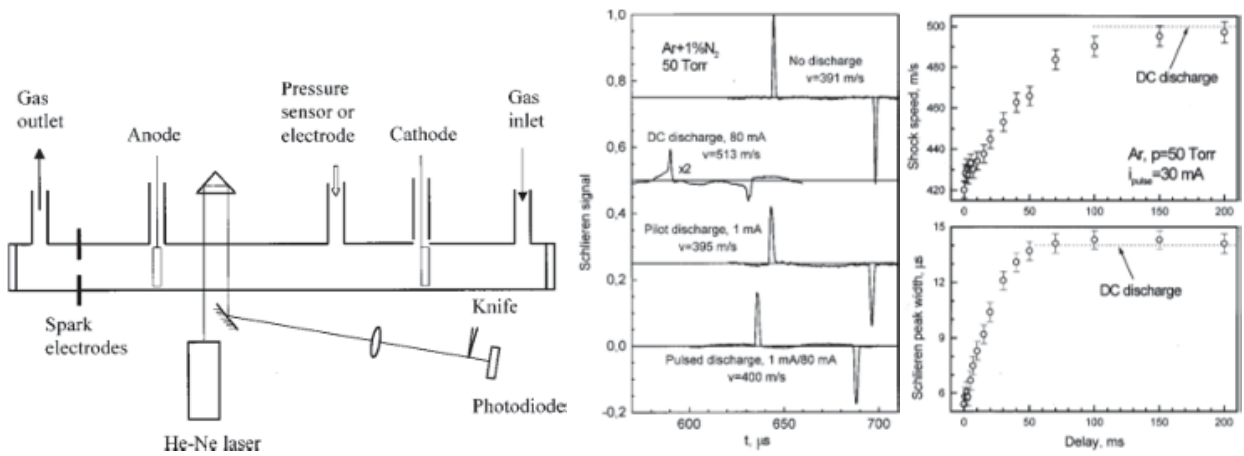

Fig. 7. a) Schematic of the experimental setup for studies of shock propagation in glow discharges; b) Schlieren signals and shock velocities in a glow discharge in Ar $+11 \% \mathrm{~N} 2$ at 50 Torr: the discharge off; 80-mA continuous dc discharge, weak (I $\sim 1 \mathrm{~mA}$ ) pilot discharge, and a pulsed discharge; c) Evolution of shock velocity and the width of the schlieren signal at a fixed location inside the discharge with time delay between the beginning of the discharge and the shock launch [Macheret et al, 2001]. 
Nevertheless, an important question about possible peculiarities of the discharge and plasma properties in molecular gases still remained. Strong excitation of internal degrees of freedom of molecular gases, electrons attachment and lower electron temperatures (strong influence of electrical double layer under low ionic Mach number) could lead to significant influence of non-equilibrium excitation on plasma-shock interaction. The clarification was done in papers [Khorunzhenko et al, 2003; Anokhin et al, 2004].

Papers [Khorunzhenko et al, 2002,2003] describe the results of measurements of the structure of the strong shock waves in plasma with strong electric fields $(E / n \sim 10 \mathrm{kTd})$. The authors obtained profiles of gas rotational temperature, distribution of electron number density and electric field in air flow at $\mathrm{M}=8.2$. Comparison of the experimental results and numerical modeling showed that drag change can be totally explained by gas heating during energy thermalization under plasma relaxation (Figure 8).
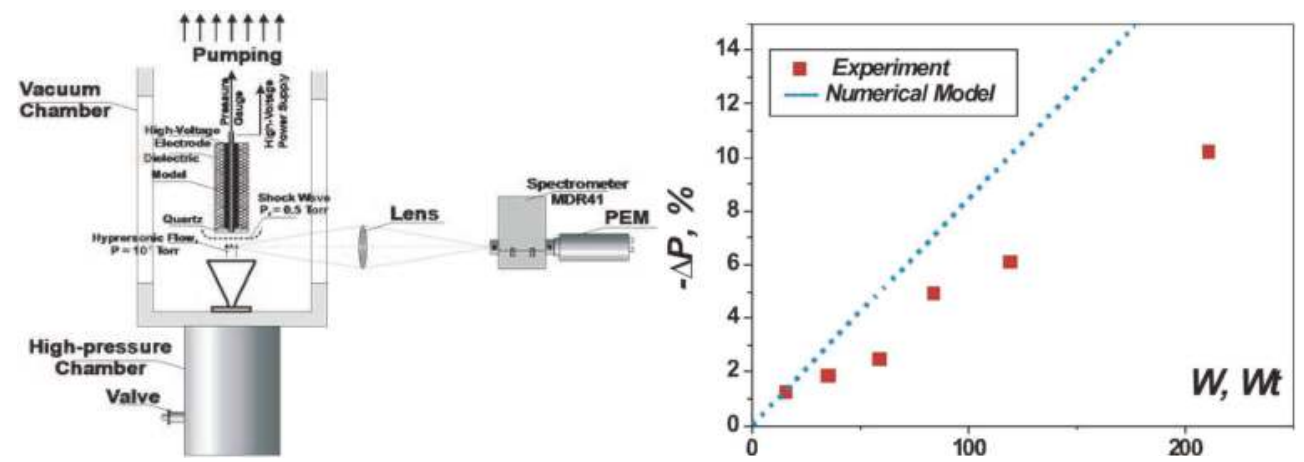

Fig. 8. a) Organization of hypersonic plasma flow. b) Comparison of the experimental results and numerical modeling of stagnation pressure variation vs discharge power in $\mathrm{M}=8.2$ air flow [Khorunzhenko et al, 2003].
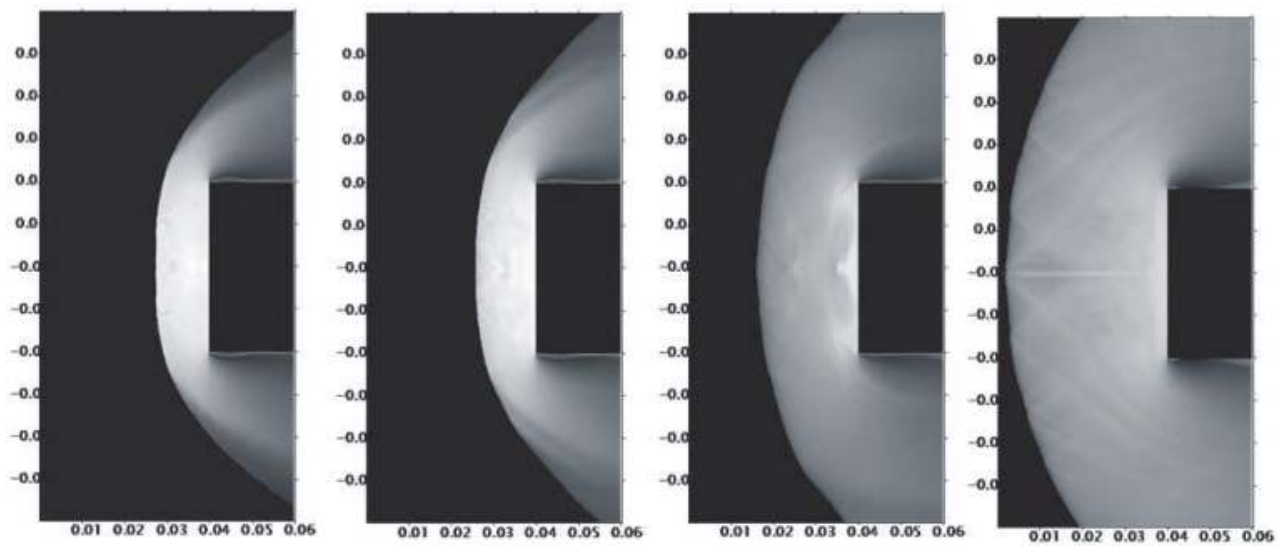

Fig. 9. Flow field calculation for different discharge energy deposition. a) discharge is OFF; b) $\mathrm{E}=0.044 \mathrm{eV} / \mathrm{mol}$; $) \mathrm{E}=0.049 \mathrm{eV} / \mathrm{mol}$; d) $\mathrm{E}=0.054 \mathrm{eV} / \mathrm{mol}$. Air, $\mathrm{M}=8.2, \mathrm{~T}_{0}=300 \mathrm{~K}$, $\mathrm{P}_{0}=35$ Torr, $\mathrm{T}_{1}=21 \mathrm{~K}, \mathrm{P}_{1}=5 \cdot 10^{-3}$ Torr [Khorunzhenko et al, 2003]. 
Figure 9 demonstrates the computed flow field change for different discharge power. Main energy release occurs behind shock wave front due to higher gas number density, and, consequently, higher energy deposition by discharge, in electron-ion recombination processes.

Paper [Anokhin et al, 2004] presented the investigations of shock wave propagation through the pulsed nanosecond discharge decaying air plasma $(E / n \sim 600-800 \mathrm{Td})$. It was discovered that the velocity of the shock wave propagation increases as the delay time increases. The delay time here means the time between discharge switching off and shock wave entering into the plasma region. This observation made it possible to prove the thermal nature of such interaction and estimate the plasma thermalization time (Figure 10).
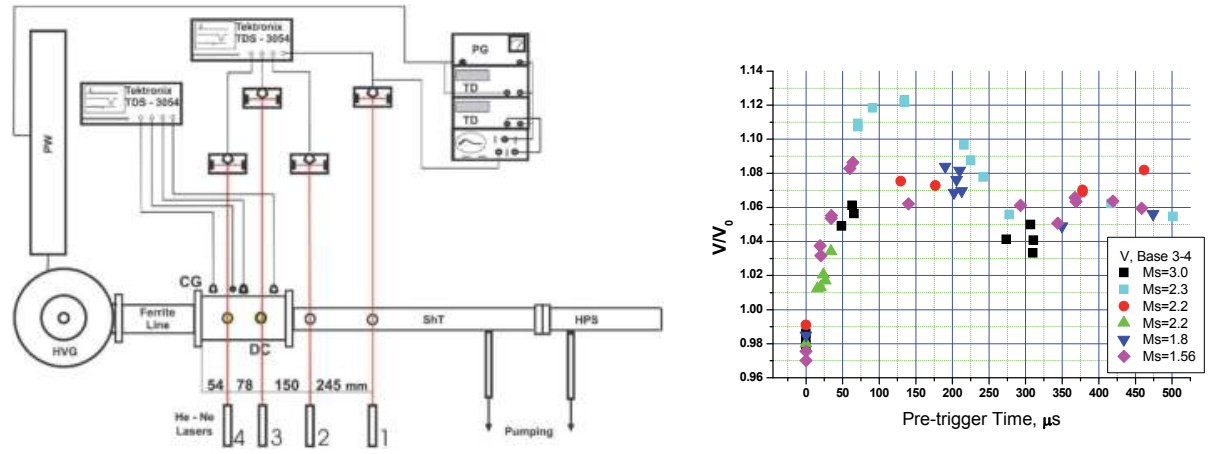

Fig. 10. Plasma shock tube schematics a) and shock wave acceleration in the plasma region in dependence on the plasma relaxation time [Anokhin et al, 2004].

Thus the results of papers [Miles et al, 2001, Meyer et al, 2003, Khorunzhenko et al, 2003; Anokhin et al, 2004] clear demonstrate the thermal nature of the shock wave - plasma interaction. Theory of shock wave interaction with hot layers (and, in fact, with entropy layers of any nature) was developed long ago.

Publications by group of Nemchinov (see, for example, [Nemchinov et al, 1989]) show that the length of the pre-cursor for sufficient overheating of hot layer depends linearly on the shock wave's run-up distance along the hot layer:

$$
l \approx U_{s} t
$$

This relation was checked up to $U_{s} t=(80-90) h$ for planar thermal layer (2D flow), and $U_{s} t=(300-400) d$ for thermal channel (axisymmetric). This means that the mechanism should exist which will provide the gas accumulation in the precursor zone both from the hot layer and undisturbed flow region. One of possible variants of such a structure is the hot layer detachment from the axis or plane of symmetry and vortex structure formation.

In [Nemchinov et al, 1989] it was found that up to overheat value of $T / T^{\prime} \cong 2.5$ the ratio of the precursor length and the shock wave run-up distance along the hot layer is in the range of $\xi=0.02 \div 0.05(M=3, \gamma=1.4)$, and only starting from the overheat value of $T / T^{\prime}>2.5$ demonstrated the dependence from the overheat value, reaching the value $\xi=0.29$ at $T / T^{\prime}>5.5$. Initially the criteria of the flow rearrangement has been proposed by Mark [Mark, 1957] and Griffiths [Griffiths, 1957] right after the first tests of the ultra-powerful bombs, where the emission from the epicenter causes a hot layer formation above the Earth surface and 
intensive blast wave interaction with this layer. A Mark-Griffiths criterion was based on the comparison of the stagnation pressure of the gas from entropy layer and static pressure of the gas from main flow. It was assumed that shock wave velocity in entropy layer and outside the layer are the same at least until the moment when critical conditions appear. One can see that the condition of equal velocity of the shock wave front in all regions defacto forbids the flow rearrangement even when the Mark-Griffiths criterion will meet. It indicates on the internal contradictions in the model. Indeed, the Mark-Griffiths criterion at $\mathrm{M}=3, \gamma=1.4$ estimates the threshold of a global flow restructuring close to $\mathrm{T} / \mathrm{T}^{\prime}>1.18$, which is significantly different from the values observed $\left(\mathrm{T} / \mathrm{T}^{\prime}{ }_{\text {crit }} \cong 2.5\right)$.

Paper [Lashin\&Starikovskii, 1995] suggests a modification of the Mark-Griffiths criterion. As criterion of flow modification from initial stable shock wave propagation to self-similar precursor growth to conditions should be satisfied:

1. Static pressure behind the SW in the entropy layer should be equal to the static pressure behind SW in the main flow;

2. Gas velocity behind the SW in the entropy layer should be equal to the velocity of SW propagation in the main flow.

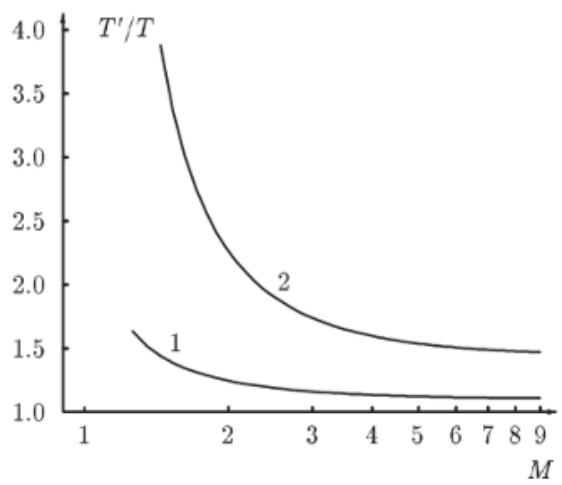

Fig. 11. Dependence of the critical layer overheating $\left(T / T^{\prime}\right)_{\text {crit }}$ on the shock wave Mach number. $\gamma=1.4$. 1) - Mark-Griffiths criterion, 2) - modified criterion [Lashin\&Starikovskii, 1995].

The conditions 1) and 2) means the complete deceleration of gas from the entropy layer with respect to the main shock wave front in the plane shock wave. Mathematical details can be found elsewhere [Lashin\&Starikovskii, 1995], while here we give the final expression for the critical overheating of the longitudinal thermal layer, which initiates a self-similar growth of the shock wave front precursor:

$$
\left(\frac{T^{\prime}}{T}\right)_{c r i t}=\left(\frac{M_{s}^{2}}{M_{S}^{2}-1} \frac{(\gamma+1)}{2}\right)^{2}
$$

This criterion quantitatively reproduces existing experimental results on the shock-wave hot layer interaction and allows to perform an analysis of the energy needed for supersonic flows control with the help of hot layers (Figure 11).

Another important question is the minimal possible thickness of the entropy layer to achieve a stable interaction. Minimization of the layer thickness means the energy consumption minimization and is extremely important from the point of view of practical 
flow control. Based on the results [Nemchinov et al, 1989] the self-similar solution exists at least up to run-up distance $d x=(300-400) d$ with the dynamics of precursor length increase close to $1 \sim 0.3 \mathrm{dx}$. These relations show that one can expect the shock wave pattern change even using the entropy layer diameter of about $1 \%$ of the object. Figure 12 shows the example of interaction of the entropy layer of different size with a bow shock. For relative layer thickness of $10,100 \%$ and excitation of the entire flow the stagnation pressure decrease relative to unexcited flow was 21,34 and $29 \%$ respectively. It is clear that the decrease of the entropy layer size allows significantly increase the efficiency of flow control.
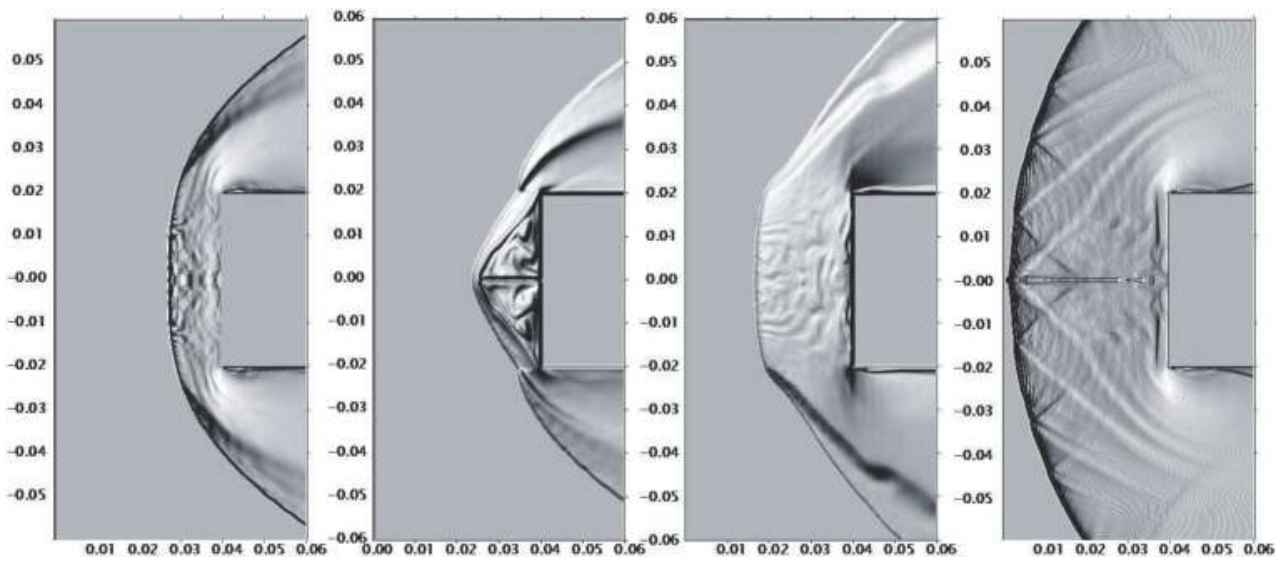

Fig. 12. Numerical model of hot layer - shosk wave interaction. The influence of layer thickness. Air, $M=8.2, T_{0}=300 \mathrm{~K}, P_{0}=35$ Torr. Excitation energy is $E=0.054 \mathrm{eV} / \mathrm{mol}$, layer thickness is a) $0 \%$; b) $10 \%$; c) $100 \%$ and d) entire flow [Opaits et al, 2004].

Approximately equal effect of thin and thick entropy layers on the shock waves configuration allows to use focused and relatively weak excitation of the gas ahead of the shock wave front. That is why many experiments on drag reduction control by plasma were performed with thin filaments generation [Azarova et al, 2011]. As examples we will mention the pulsed laser energy deposition [Adelgren et al, 2001], MW filaments generation [Kolesnichenko et al, 2004], counter-flow jet injection [Shang, 2002].

Papers [Adelgren et al, 2001, 2001, 2002] examined the effect of pulsed energy deposition on the flow past a sphere at $M_{1}=3-4.5$. A Nd:YAG laser $(532 \mathrm{~nm}, 10 \mathrm{~ns}$ pulse duration, $10 \mathrm{~Hz}$ repetition rate) was used in all experiments with energy levels from 12 to $300 \mathrm{~mJ}$. The first configuration is an isolated sphere. A single laser pulse generates a thermal spot upstream of the bow shock. The interaction of the thermal spot with the bow shock is shown in Fig. 13.

In Ref. [Shang, 2002] it was presented a possibility of control of shock wave structure and decrease of the drag due to thermal gas heating by injecting a hot plasma jet toward the main flow. Drag measurements were made with both fluid injection and plasma jet injection. Experiments were conducted at Mach 6. A plasma torch was used to inject a counter-flow at Mach 3.28. Plasma jet injection from a spherically blunted cylinder can significantly reduce drag. Schlieren images of the experimental and calculated flow patterns are shown in Figure 14. 

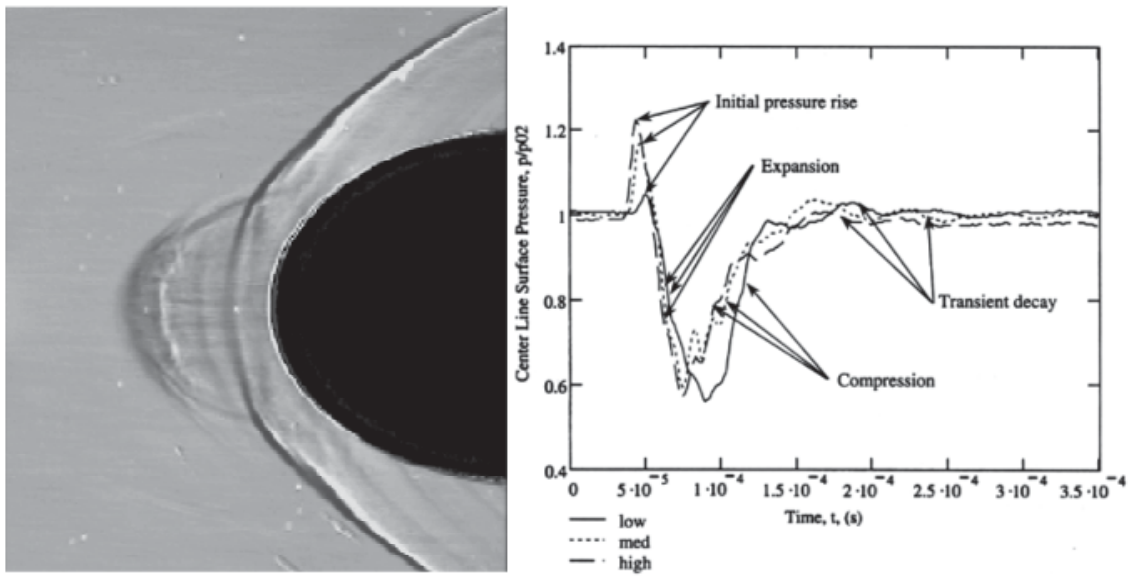

Fig. 13. a) Bow shock interaction with a laser-generated hot spot. b) Temporal behavior of the stagnation pressure on the body centerline for energy pulses energy $13 \mathrm{~mJ}$ (low), $127 \mathrm{~mJ}$ (med) and $258 \mathrm{~mJ}$ (high) [Adelgren et al, 2002].

Figure 13,b confirms very weak dependence of the interaction dynamics for all perturbations above the strong interaction threshold (see equation (1)).
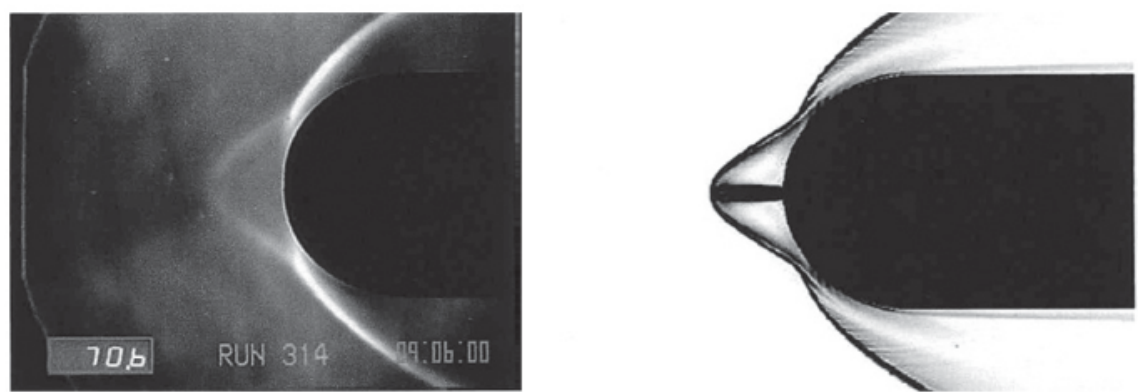

Fig. 14. a) Schlieren picture of counter-flow experiment. b) Calculated flow patterns of counter-flow configuration [Shang, 2002].

Paper [Kolesnichenko et al, 2004] presented the results of controlling the bow shock wave structure with a thin plasma layer formation by applying microwave discharge. The filament, which is formed in 1-2 ns and has a radial dimension of less than $3 \times 10^{-3} \mathrm{~cm}$, has a specific energy of approximately $7 \mathrm{eV}$ per particle with a peak $n_{\mathrm{e}} \approx 5 \times 10^{16} \mathrm{~cm}^{-3}$. The temperature rise in the filament is approximately $2800 \mathrm{~K}$ with a heating rate of $\sim 2000-3000 \mathrm{~K} / \mu \mathrm{s}$. Time-resolved measurements show that the discharge significantly alters the bow shock configuration due to hot filament formation. Figure 15 demonstrates the bow shock propagation forward into the hot zone, forming the same structure as it is observed for typical hot layer - shock wave interaction (Figure 12). The interaction of the filaments with the bow shock waves after 60 and $85 \mu$ is shown in the Schlieren images (Figure 15, left), and the vortices can be seen as a bright regions in luminosity distribution fields (Figure 15, right). 


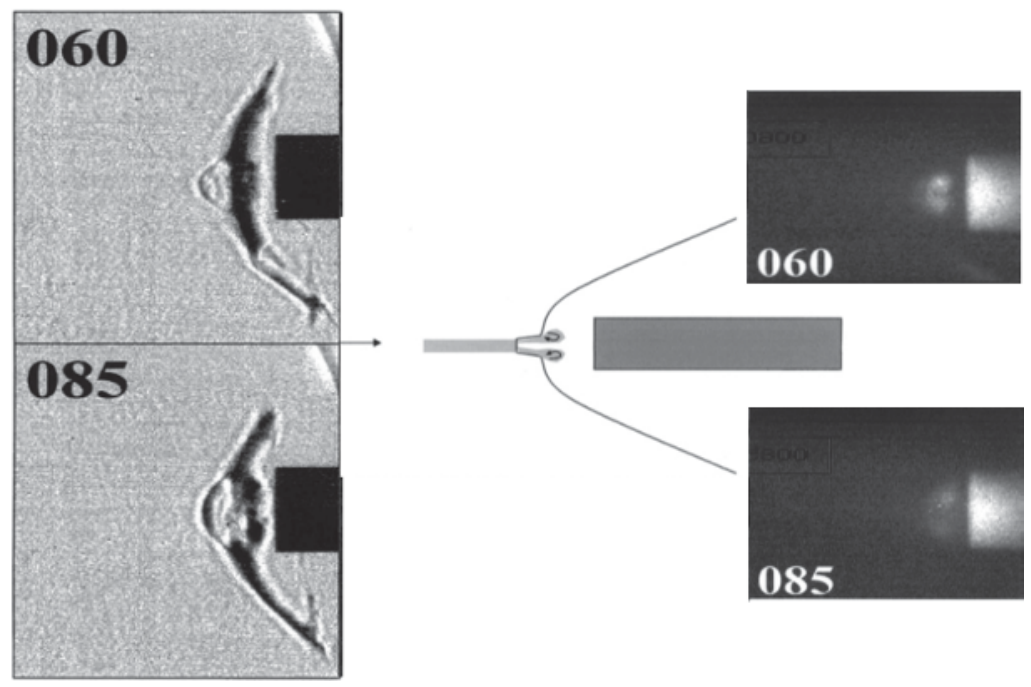

Fig. 15. Interaction of microwave filament with blunt body flow. Left - Schlieren images; right - luminosity distribution fields. 60 and $85 \mu$ s after the MW discharge [Kolesnichenko et al, 2004].

In [Kolesnichenko et al, 2004] it was shown that the energy efficiency of the stagnation pressure reduction is directly proportional to $(D / d)$ ratio, where $D$ and $d$ are the model and discharge filament diameter, respectively. The validity of this scaling relationship was proved for model diameters between 8 and $30 \mathrm{~mm}$. These results confirm the conclusion of [Nemchinov et al, 1982; Lashin\&Starikovskii, 1995] about interaction efficiency increase and for reducing aerodynamic drag when the hot layer's thickness decreases.

As a summary for this part we can conclude that the experiments demonstrate high efficiency in generating small areas of heated gas and controlling configuration of the shock waves and flow pattern. Plasma effects, such as spatial charges and double-layer formations, do not seem to significantly impact the propagation of strong shock waves.

The main problem of supersonic and hypersonic flow control is the technology of hot filament generation ahead of the leading shock wave. It is necessary to generate a plasma filament with controlled properties and location in the low-density region in front of the shock wave. The problem is clearly demonstrated in recent paper [Erdem et al, 2011]. The paper presents the effect of energy deposition via arc discharge on $15^{0}$ half-angle truncated cone-cylinder configurations and a truncated cone with flare configuration in Mach 5 flow. To initiate the arc discharge the authors should place high voltage tungsten electrode ahead of the model (Figure 16). The arc discharge influence is much weaker than the influence of the electrode in front of model. Besides, the electrode system will be blown away in almost all practical conditions.

Current methods under consideration include DC electric fields, RF fields, microwaves, lasers, electron beams and short pulsed high voltage electric fields [Macheret et al, 2001]. In all cases we have to aviod the energy release behind shock wave front to avoid an additional heat fluxes. A combination of several methods such as the use of jets, laser beams or e-beams to localize MW or pulsed DC energy release may be considered. 

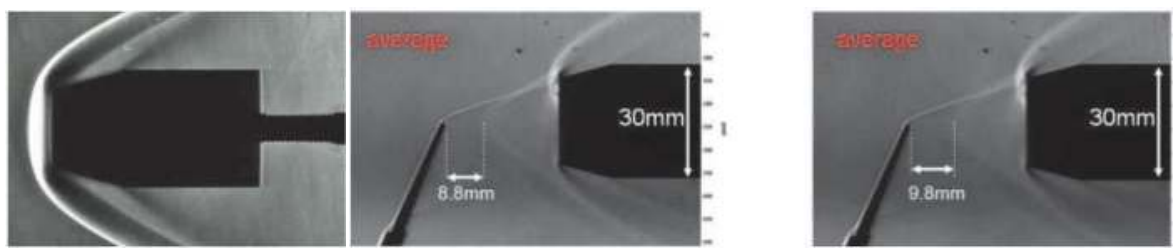

Fig. 16. Comparison of a) base; b) discharge-off and c) b) discharge-on cases in terms of averaged Schlieren images over a truncated cone-cylinder [Erdem et al, 2011].

\section{MHD flow control}

The history of MHD concept for flow control actually was started even earlier than AJAX concept. A wide range of MHD flow-control opportunities has been suggested: MHD flow control for inlet mass flow and shock position control, MHD flow turning and separation control; MHD power generation; MHD heat transfer reduction at leading edges; MHD flow control for control surfaces [Van Wie et al, 2004].

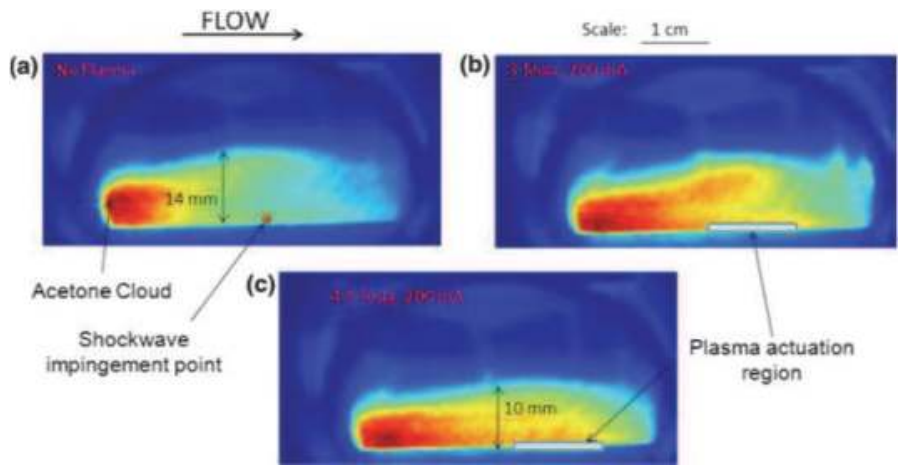

Fig. 17. Time averaged side view of the separation as visualized by acetone PLS with the shock impingement location moved downstream by $2 \mathrm{~d}$, (a) base line case with no plasma actuation, (b) plasma actuation at 3 Tesla and (c) plasma actuation at 4.5 Tesla [Karla et al, 2010].

The practical implementation of MHD technologies for aerospace applications faces three major problems: magnetic field generation; gas ionization; plasma recombination. That is why despite of very clear theoretical basis the experimental demonstrations of MHD flow control are very limited.

The paper [Karla et al, 2010] demonstrates the potential for shockwave-turbulent boundary layer interaction control in air using low current DC constricted surface discharges forced by moderate strength magnetic fields. Experiments are conducted in a Mach 2.6 in draft air tunnel with discharge currents up to $300 \mathrm{~mA}$ and magnetic field strengths up to 5 Tesla. The effect of plasma control on boundary layer separation due to interaction with shock wave depends on the direction of the Lorentz force. If shock-induced separation is present, it is observed that by using Lorentz force that pushes the discharge downstream, separation can be suppressed (Figure 17). Electron density was maintained by DC grow discharge on the level of $\mathrm{n}_{\mathrm{e}} \sim 2.9 \times 10^{12} \mathrm{~cm}^{-3}$. 
Extensive experimental work on the problem of MHD flow control has been conducted by a team of researchers at the Ioffe Physical Technical Institute led by Bobashev [Lapushkina et al, 2011]. The papers [Erofeev et al, 2010; Lapushkina et al, 2009] discusses the MHD influence on the flow (velocity $\sim 2 \mathrm{~km} / \mathrm{s}$, Mach number $=4$ ). Two models in the shape of a cone mated with a cylinder were used. At the cone vertex and along the mating line two electrodes were located, and inside the cylindrical parts magnetic inductors were housed. One of the models was equipped with a magnetic core inside the inductor (Figure 18). An appreciable difference between the influences on the gas flow about these two models was detected. Measurements of the heat flux toward the surfaces of the models were carried out. It was found that the induction of the magnetic field appreciably influence on the local heat load.
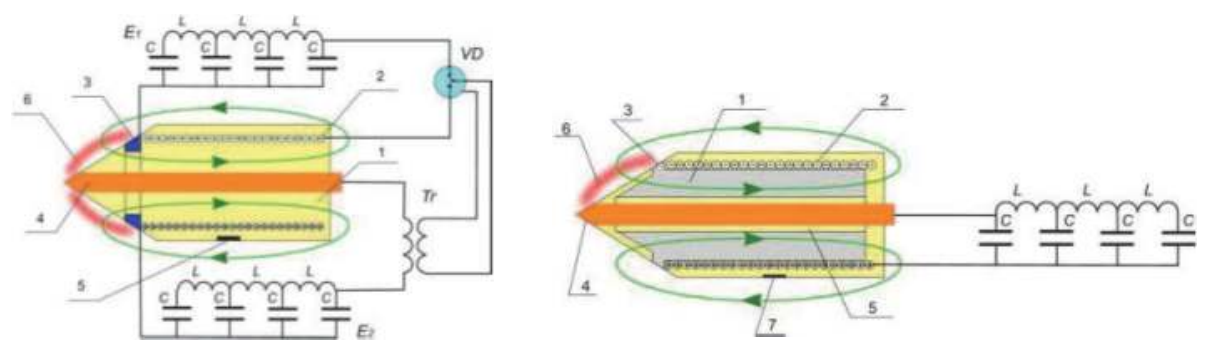

Fig. 18. Model geometry a) without; b) with magnetic core [Lapushkina et al, 2009].

Figure 19,a shows Schlieren patterns of the flow for the model with the core (left) and without core (right). The maximum magnitudes of the current and magnetic induction amounted to $I_{\mathrm{m}}=1.7 \mathrm{kA}$ and $B_{\mathrm{m}}=0.3 \mathrm{~T}$ for the model without core, and $I_{\mathrm{m}}=1.5 \mathrm{kA}$ and $B_{\mathrm{m}}=0.7 \mathrm{~T}$ for the model with the core, respectively. Figure $22, \mathrm{~b}$ shows signals of the heat sensor located on the cylindrical surface of the model containing the magnetic core. In the plot there are signals at various discharge currents and magnetic inductions $\left(I_{\mathrm{m}}=1.3 \mathrm{kA}\right.$, $B_{\mathrm{m}}=0.6 \mathrm{~T}$ and $I_{\mathrm{m}}=1.5 \mathrm{kA}, B_{\mathrm{m}}=0.7 \mathrm{~T}$ ) obtained at the positive and negative polarities of the ring electrode [Lapushkina et al, 2009].
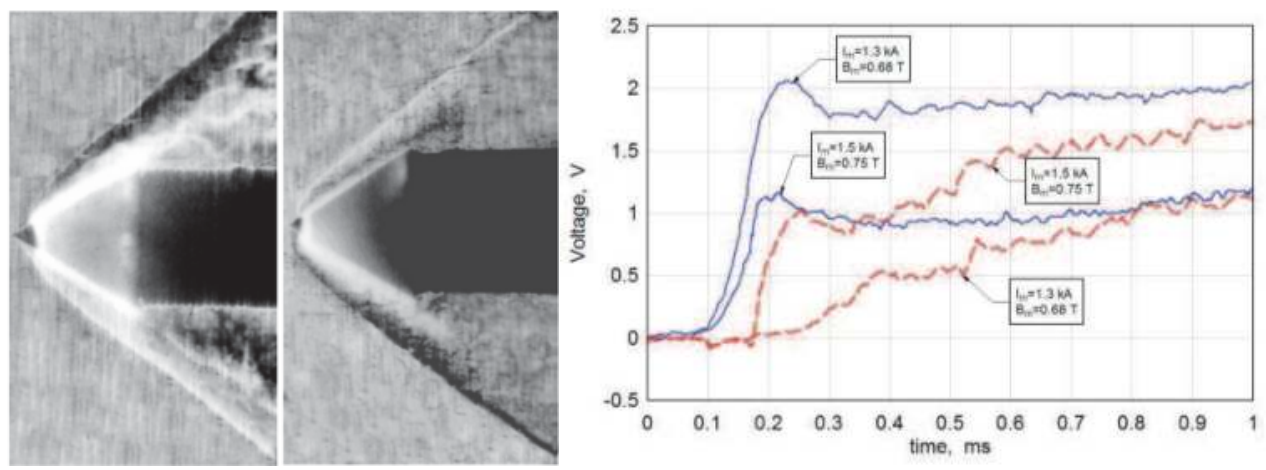

Fig. 19. a) Schlieren patterns of the flow about the model with the magnetic core (left) and without core (right). b) Oscillograms of the signals of the heat flux sensors installed on the model with the core at the positive (dashed lines) and negative (solid lines) polarities of the ring electrode and various discharge currents [Lapushkina et al, 2009]. 
When increasing the discharge current and magnetic induction the magnitude of the signal of the heat sensor varies differently: when the ring electrode is positive the mean magnitude of the signal increases, and at the negative polarity of the ring electrode the signal decreases (Figure 19,b).

Another series of experiments at the Ioffe Physical Technical Institute have been conducted using a shock tunnel (Figure 20) operating with rare gases (krypton, xenon and argon) to produce an ionized gas flow [Bobashev et al, 2006].

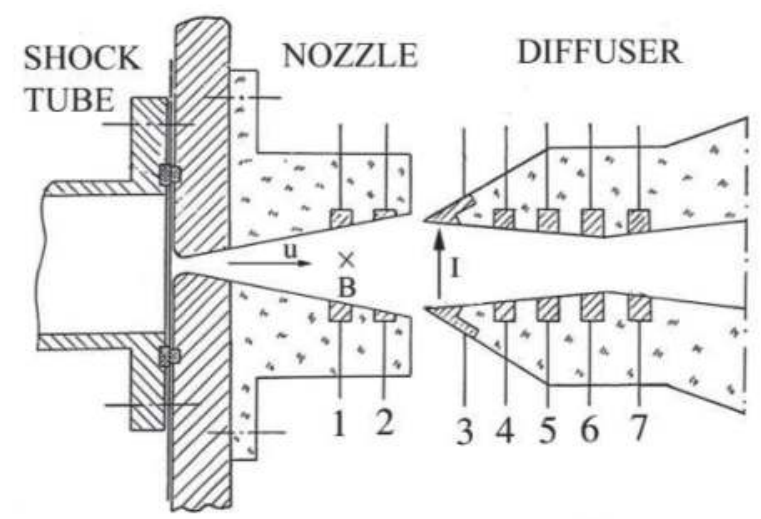

Fig. 20. Scheme of MHD channel with electrodes [Bobashev et al, 2006]. Figures are numbers of electrodes. $U$ is flow velocity, $\mathrm{B}$ is magnetic field, I is current.

The experiments shown in Figure 21 were carried out in Xe. In this case the magnetic field influence on a change in the Mach number, when flow enters into the diffuser, should be predominated one at $\mathrm{B}>0.8 \mathrm{~T}$.

a)

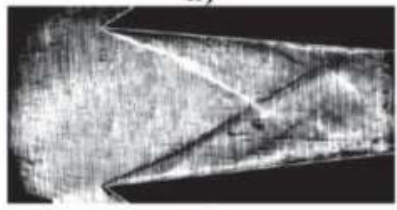

b)

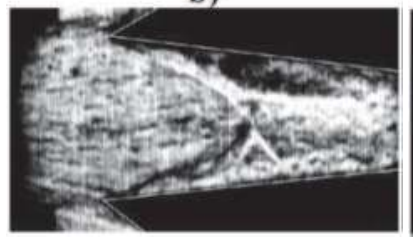

a)

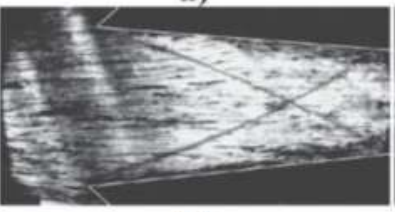

b)

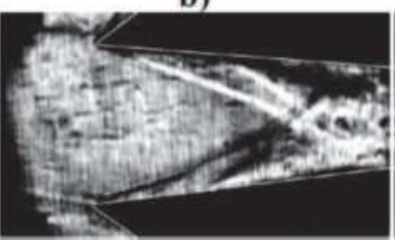

a)

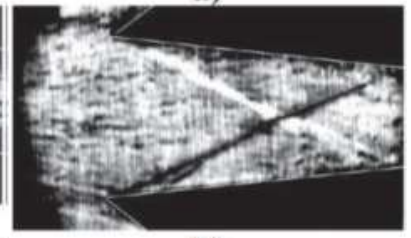

b)

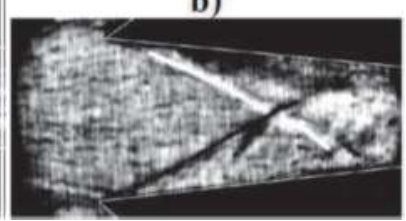

Fig. 21. Schlieren pictures of the flow in the case I, II and III (left to right). (a) V=110 V, B=0; (b) $\mathrm{V}=110 \mathrm{~V}, \mathrm{~B}=1.3 \mathrm{~T}$ [Bobashev et al, 2006].

In Figure 21 showed are the distinguished region of the diffuser functioning as the Faraday channel with the sectioned electrodes: I - a whole diffuser, the electrodes from $3^{\text {rd }}$ to $7^{\text {th }}$ pairs 
functioning; II - a region of the diffuser, the inlet section excluded, a current goes via 4-7th pairs of the electrodes; III - the inlet section, A current goes only via $3^{\text {rd }}$ pair of the electrodes. All the electrodes are supplied with an equal voltage $\mathrm{V}=110 \mathrm{~V}$, the experiment was carried out at B $=1.3 \mathrm{~T}$. In Figure 21 showed are the Schlieren images of a flow obtained at the different commutations of a current.

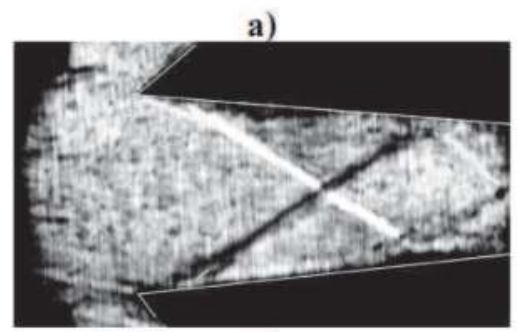

b)

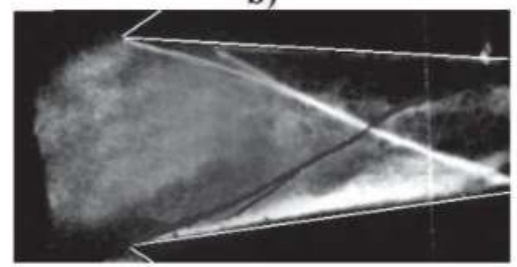

Fig. 22. Examples of variations in shock-wave configurations under the action of electric and magnetic fields. a) deceleration regime; b) acceleration regime

[Bobashev et al, 2006].

Experiments shown in Figure 21 revealed a strong effect of Joule heating [Bobashev et al, 2006]. The aim of experiment demonstrated in Figure 22 was to separate the action of ponderomotive force and Joule heating. In this series of experiments interaction with magnetic and electric fields was localized in a short inlet part of the diffuser, i.e., where the action of the fields is most efficient [Bobashev et al, 2006]. Authors [Bobashev et al, 2006] underlined that the hypersonic MHD experiments should be performed in air flow ionized by the external power sources, but at present air ionization in the diffusers is questioned and require additional investigations.

Below we will illustrate general principles and problems of MHD flow control using an example taken from the review [Van Wie, 2004]. A schematic of MHD inlet flow control system is shown in Figure 23. The concept proposed in [Van Wie et al, 2004] incorporates a large 5-m diameter magnet located in the forward end of the forebody to produce a 3-T field at the surface. A 1D array of e-beam guns is located within the magnet to inject high-energy electrons along the magnetic field lines. The e-beam energy is enough to provide sufficient ionization at a distance of 2.2-m from the surface. Electrodes are located on either side of the e-guns to collect the transverse MHD current. Figure 24 shows predicted flowfield of MHDcontrolled $\mathrm{M}_{\mathrm{DES}}=5$ inlet operating at Mach 10 [Schneider et al, 2004]. The temperature contours show that the MHD flow control is successful in repositioning the forebody shocks at the cowl lip. The narrow MHD interaction region is seen in the contours of the electron density. 


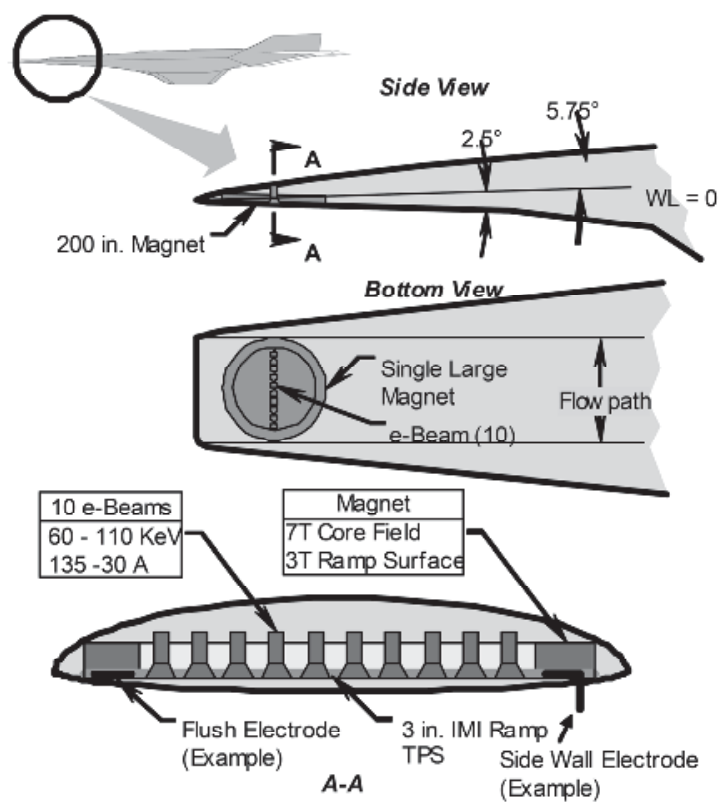

Fig. 23. MHD inlet control system [Van Wie, 2004].
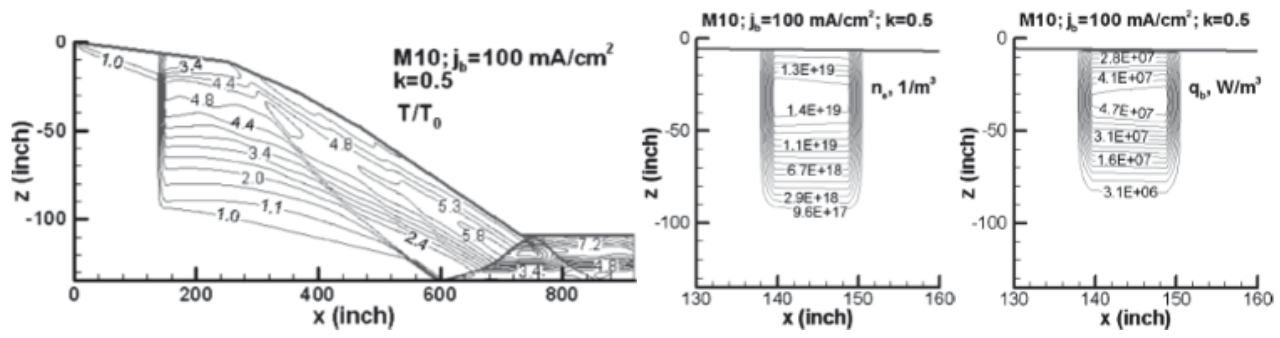

Fig. 24. Predicted flowfield of MHD-controlled $M_{D E S}=5$ inlet operating at Mach 10. a) Temperature field; b) Electron density field; c) Beam power [Schneider et al, 2004].

Estimations of [Schneider et al, 2004] show that the flow control system can operate in a selfsustained mode with the $\sim 76 \mathrm{MW} / \mathrm{m}$ power extracted, while a power required for the ionization system is less than $29 \mathrm{MW} / \mathrm{m}$. This extremely important conclusion requires some additional comments. First, to achieve a high efficiency of MHD interaction extremely heavy 3.5-T magnets are proposed; second, the interaction efficiency is limited by the efficiency of gas ionization by e-beams (energy required is $\sim 34 \mathrm{eV}$ per electron-ion pair); and third, the region of interaction is limited by plasma life time - i.e., rate of nonequilibrium plasma recombination. It should be noted that in [Schneider et al, 2004] the only recombination channel, dissociative recombination with simple molecular ions, was taken into account (the rate coefficient $k=2 \times 10^{-7}\left(300 / T_{e}\right)^{1 / 2}$, where $T_{e}$ is the electron temperature). The energy efficiency of gas ionization by high-energy e-beam is well-known. Energy threshold for nitrogen ionization is $\sim 15.6 \mathrm{eV}$, and similar energy is spent on excitation and 
dissociation of the molecules. As a result, the energy cost for electron-ion pair production in air under the action of high-energy electrons is $33-34 \mathrm{eV}$.

There are several mechanisms of electron loss that lead to a decrease in the conductivity of a nonequilibrium molecular plasma. They are dissociative electron- ion recombination, threebody electron-ion recombination, the third body being a molecule or electron, and electron attachment to molecules. Under the conditions typical for MHD applications, electron density is sufficiently high to neglect electron attachment as compared to electron-ion recombination.

In [Schneider et al, 2004], it was assumed that the dominant mechanism of electron loss is electron recombination with simple positive ions such as $\mathrm{O}_{2}{ }^{+}$and $\mathrm{N}_{2}{ }^{+}$. This is not valid in an air plasma at room temperature at which simple ions are usually transformed to complex ions such as $\mathrm{O}_{4}{ }^{+}$and $\mathrm{N}_{4}{ }^{+}$. The rates of dissociative recombination for complex ions are an order of magnitude higher than the rates of dissociative recombination for simple ions [FlorescuMitchell\&Mitchell, 2006]. Therefore, the lifetime of the plasma was overestimated in [Schneider et al, 2004] approximately by an order of magnitude. This follows also from direct measurements of the effective recombination rates in room temperature $\mathrm{N}_{2}, \mathrm{CO}_{2}$ and $\mathrm{H}_{2} \mathrm{O}$ under conditions close to those for MHD-controlled inlets were performed in papers ([Zhukov et al, 2006; Aleksandrov et al, 2007a,2007b,2008,2009]), and in air in paper [Aleksandrov et al, 2011].

Discharge was initiated in a quartz tube of inner diameter $47 \mathrm{~mm}$ and outer diameter 50 $\mathrm{mm}$, the metallic electrodes being at the ends of the tube. Observations were made for gas pressures between 1 and 10 Torr. Pulses of amplitude $11 \mathrm{kV}$ in cable, duration $25 \mathrm{~ns}$ at halfheight and rise time $5 \mathrm{~ns}$ were supplied to the electrodes (Figure 25). The time-resolved electron density was measured by a microwave interferometer for $\left(f=9.4 \times 10^{10} \mathrm{~Hz}\right.$, a wavelength of $3 \mathrm{~mm}$ ) initial electron densities in the range $8 \times 10^{11}-10^{12} \mathrm{~cm}^{-3}$ and the effective electron-ion recombination coefficient was determined. It was shown that this coefficient varies in time and depends on pressure. A numerical simulation was carried out to describe the temporal evolution of the densities of charged particles under the conditions considered. A good agreement was obtained between the calculated and the measured electron density histories. It was shown that the loss of electrons is governed by dissociative recombination with complex ions, their density being dependent on pressure.
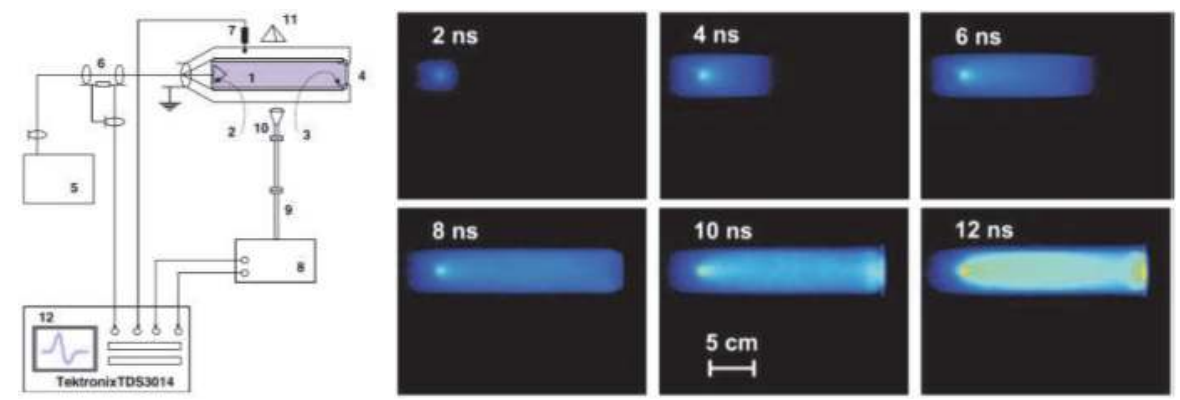

Fig. 25. a) schematic diagram of the experimental setup: (1) quartz discharge tube, (2) highvoltage electrode, (3) low-voltage electrode, (4) end CaF2 window, (5) high-voltage generator, (6) back-current shunt, (7) capacitive gauge, (8) main block of the interferometer, (9) wave guide, (10) horn antenna, (11) reflector and (12) oscillograph; b) ICCD images of nanosecond discharge in air. ICCD gate is equal to $1 \mathrm{~ns}$, time moments from the discharge start are indicated. High voltage electrode is on the left hand side [Aleksandrov et al, 2007a]. 
The plasma life-time $\tau_{1 / 2}$ was determined at the beginning of the plasma decay or later, at the instant at which $n_{\mathrm{e}}$ decreases to $2 \times 10^{11} \mathrm{~cm}^{-3}$ (Figure 27). In all gases considered, the coefficient $a_{\text {eff }}$ varies in time in the afterglow and depends on pressure. Huge effective recombination coefficient $a_{\text {eff }}$ (in comparison with dissociative recombination coefficient used in [Schneider 2004]) has been explained by extremely fast formation of complex ions. For example, in nitrogen we have [Aleksandrov et al, 2007a, 2007b]:

$$
\begin{aligned}
& \mathrm{e}+\mathrm{N}^{+} \Rightarrow \mathrm{N}+\mathrm{N} \\
& \mathrm{e}+\mathrm{N}^{+}{ }_{4} \Rightarrow \mathrm{N}_{2}+\mathrm{N}_{2}
\end{aligned}
$$
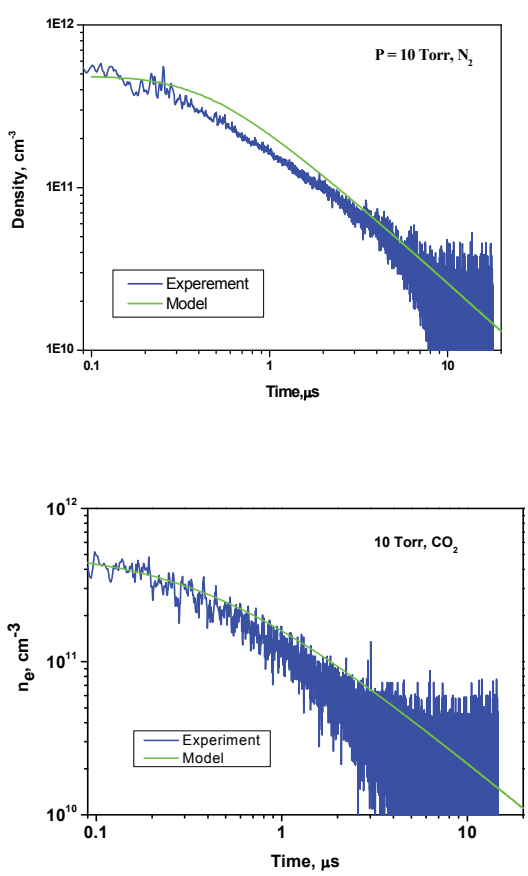

$$
\begin{aligned}
\mathrm{k}_{\mathrm{d}}(\text { molecular ion }) & =2.8 \times 10^{-7}\left(300 / T_{\mathrm{e}}\right)^{1 / 2} \\
\mathrm{k}_{\mathrm{d}}(\text { cluster ion }) & =2 \times 10^{-6}\left(300 / T_{\mathrm{e}}\right)^{1 / 2}
\end{aligned}
$$
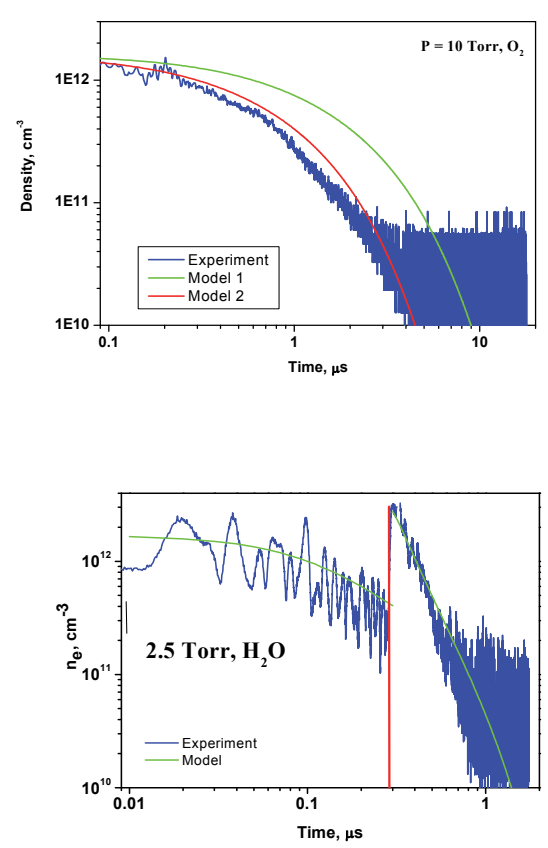

Fig. 26. Dynamics of electron density in plasma afterglow. $\left.\mathrm{T}=300 \mathrm{~K} ; \mathrm{a}) \mathrm{N}_{2} ; \mathrm{b}\right) \mathrm{O}_{2}$; c) $\mathrm{CO}_{2}$; d) $\mathrm{H}_{2} \mathrm{O}$ [Aleksandrov et al, 2007a, 2007b].

Figure 26 shows typical electron density histories measured, respectively, in $\mathrm{N}_{2}, \mathrm{O}_{2}, \mathrm{CO}_{2}$ and $\mathrm{H}_{2} \mathrm{O}$ at a discharge repetitive frequency of $2 \mathrm{~Hz}$.

The positive ion composition can be dominated by simple $\mathrm{O}_{2}{ }^{+}$ions in a high-voltage nanosecond discharge in room-temperature air (see calculations in [Aleksandrov et al, 2011]). In this case, $\mathrm{O}_{4}{ }^{+}$ions have no time to form from $\mathrm{O}_{2}{ }^{+}$ions in the discharge phase and in the discharge afterglow. However, measurements [Aleksandrov et al, 2011] showed that in this case the predominance of $\mathrm{O}_{2}{ }^{+}$ions does not necessarily lead to increasing the lifetime of the air plasma. Let us consider this point in more detail. 


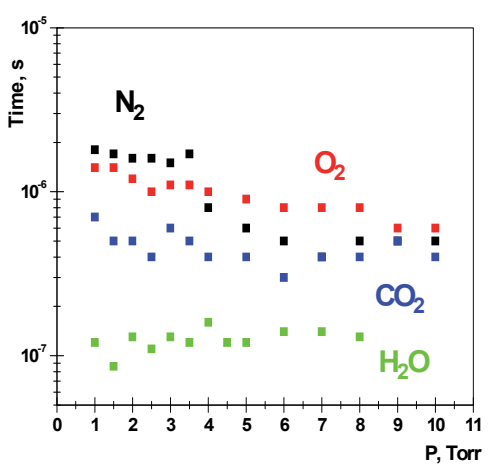

Fig. 27. Effective plasma life time in different gases [Aleksandrov et al, 2007a, 2007b].

Figure 28 compares the evolution in time of the electron density measured in [Aleksandrov et al, 2011] during the discharge afterglow and that of the electron density calculated using the generally accepted rate constants for electron loss [Kossyi et al, 1992]. The difference between the measurements and calculations reached a factor of three, much higher than the experimental error of the electron density measurements that was around $20-30 \%$. The analysis of the kinetic scheme and rate constants used showed that all rate constants were taken from measurements, with the exception of the rate of three-body electron-ion recombination

$$
\mathrm{e}+\mathrm{O}_{2}+\mathrm{e} \rightarrow \text { neutral products }+\mathrm{e} .
$$

The rate coefficient of this reaction has been measured only at $T_{e}=T>1500 \mathrm{~K}$ and only for atomic ions. It was shown in a model calculation [Collins 1965] that the rate of three-body recombination for molecular ions can be an order of magnitude higher than the rate of threebody recombination for atomic ions. The calculations with the rate of this reaction increased according to [Collins 1965] led to good agreement with the measurements (see Figure 28).

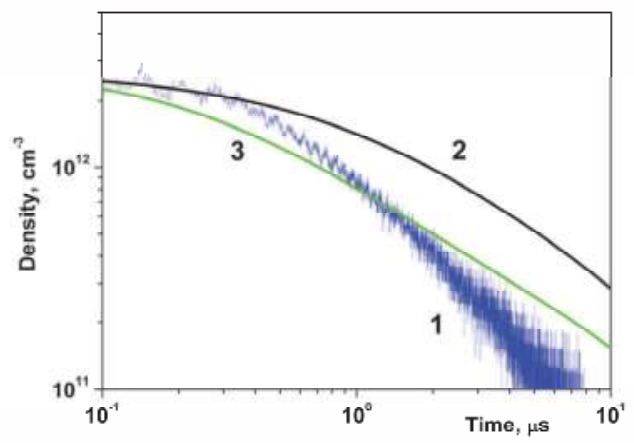

Fig. 28. The evolution in time of the electron density in the nanosecond discharge afterglow in air for 8 Torr [Aleksandrov et al, 2011]. Curve 1 corresponds to measurements.

Calculations were carried out (curve 2) with the generally accepted rate constants and (curve 3) when the rate of three-body electron-ion recombination was increased by analogy with [Collins, 1965]. 
It may be concluded that the lifetime of room-temperature nonequilibrium air plasma could be an order of magnitude shorter than that used in [Schneider et al, 2004] to estimate air plasma conductivity even when the dominant ion species is $\mathrm{O}_{2}{ }^{+}$. This means that the power required for the ionization system of MHD inlet actually is 10 times higher than estimations of [Schneider et al, 2004] and close to $\sim 290 \mathrm{MW} / \mathrm{m}$ while the power extracted remains the same $\sim 76 \mathrm{MW} / \mathrm{m}$. Power budget of MHD inlet control becomes negative and clearly demonstrates the importance of detailed kinetic mechanisms for analysis of plasma applications.

Plasma lifetime could be lengthened by an increase in the electron temperature. This occurs in the plasma decay at elevated gas temperatures. In paper [Aleksandrov et al, 2008] the results of plasma decay in air and $\mathrm{N}_{2}: \mathrm{O}_{2}: \mathrm{CO}_{2}: \mathrm{H}_{2} \mathrm{O}$ mixtures (model mixtures for GTE's outlet) at elevated gas temperatures were presented. Plasma decay after a high-voltage nanosecond discharge has been studied experimentally and numerically behind incident and reflected shock waves in high temperature (600-2400 K) air and $\mathrm{N}_{2}: \mathrm{O}_{2}: \mathrm{CO}_{2}$ mixtures for pressures between 0.05 and $1.2 \mathrm{~atm}$ (Figure 29,a). Time-resolved electron density history was measured by a microwave interferometer for initial electron densities in the range (1-3) $\times 10^{12} \mathrm{~cm}^{-3}$ and the effective electron-ion recombination coefficient was determined.
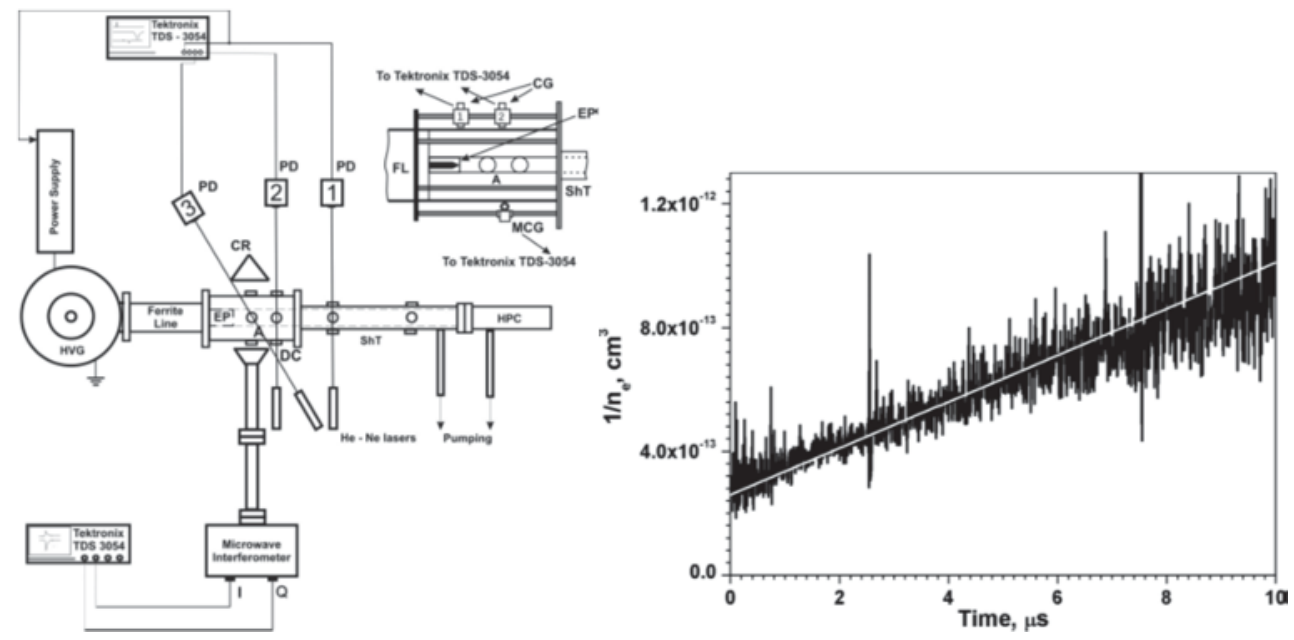

Fig. 29. A) schematic diagram of the experimental setup: (ShT) shock tube; (DC) discharge cell, (A) cross section of measurement, (EP) end plate, (HPC) high pressure cell, (HVG) high voltage generator, (PD) photodiodes, (CR) corner reflector, (CG) capacitance gauge and (MCG) magnetic current gauge. The insert shows the discharge cell on an enlarged scale. B) Typical $\left[1 / n_{\mathrm{e}}\right.$ against time] plot in air at $0.22 \mathrm{~atm}$ and $1026 \mathrm{~K}$. The white straight line corresponds to the approximation used to determine the effective recombination coefficient [Aleksandrov et al, 2008]. 
A numerical simulation was carried out to describe the temporal evolution of the densities of charged and neutral particles. It was shown that the loss of electrons in this case is determined by dissociative recombination with $\mathrm{O}_{2}{ }^{+}$ions, whereas the effect of complex ions and that of three-body recombination are negligible. Electron attachment to $\mathrm{O}_{2}$ to form negative ions is not important because of fast electron detachment in collisions with $\mathrm{O}$ atoms produced in the discharge. In the absence of $\mathrm{O}$ atoms the electron density could decay as if the loss of charged particles were governed by electron-ion recombination with the effective rate coefficient being much higher than the dissociative recombination coefficient.

It follows from the measurements [Aleksandrov et al, 2008] in the $\mathrm{CO}_{2}$-containing mixtures that $a_{\mathrm{eff}}$ is independent of gas composition and pressure (in the range 0.05-1.2 atm) and also agrees well with the dissociative recombination coefficient for $\mathrm{O}_{2}{ }^{+}$. It may be concluded that under the conditions studied electron attachment to molecules and dissociative recombination with complex $\left(\mathrm{O}_{4}{ }^{+}\right.$, etc) positive ions are unimportant. The main channel of recombination at elevated temperature conditions is dissociative recombination [Aleksandrov et al, 2008].
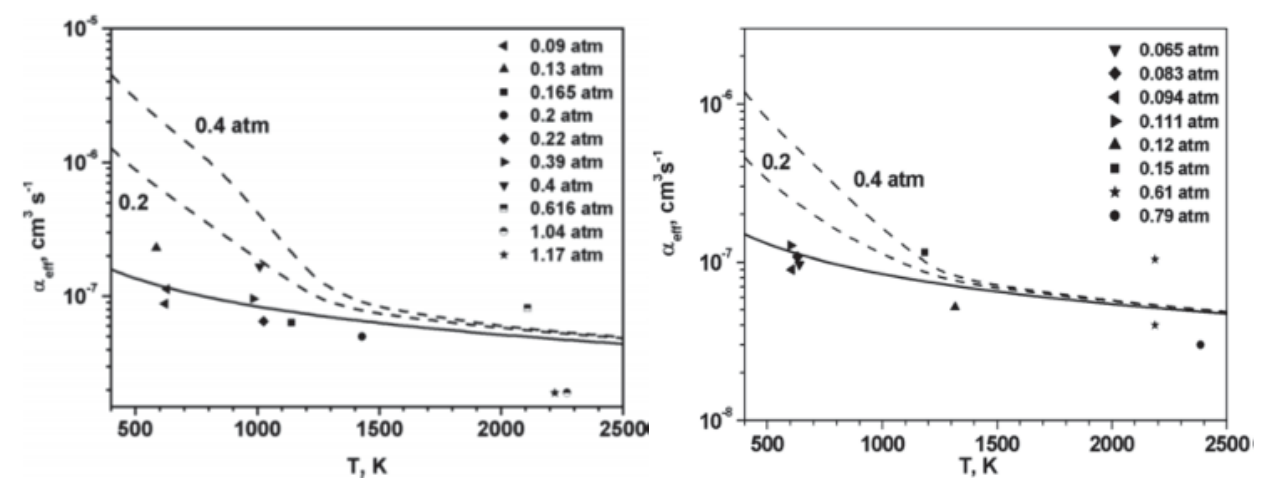

Fig. 30. The effective electron-ion recombination coefficient (symbols) as a function of temperature. The solid curve corresponds to the dissociative recombination coefficient measured in [Cunningham\&Hobson, 1972] for $\mathrm{O}_{2}{ }^{+}$and the dashed curves correspond to our calculations at various pressures in the absence of $\mathrm{O}$ atoms. A) Air; B) $\mathrm{N}_{2}: \mathrm{O}_{2}: \mathrm{CO}_{2}=86: 5: 9$ mixture [Aleksandrov et al, 2008].

\section{Boundary layer control}

On the whole, plasma governs flow through two main mechanisms, either by momentum or energy transfer.

Discharge energy transfer to the flow is a rather complicated multistep process [Raizer, 1991]. Because they possess small masses and long mean free paths, the electrons gain energy from the electric field. The slow rate of energy exchange of electrons with neutral gas results in a significant deviation of the mean electron energy from the energy of translational degrees of freedom of molecules. Depending on the value of the applied electric field, the mean electron energy in the discharge can reach several electron-volts. These conditions provide active excitation of the internal degrees of freedom of molecules, as well as their dissociation and ionization by electron impact. At the same time, the energy flux into translational and fast-thermalizing rotational degrees of freedom is relatively low. 
Consequently, the energy release at VT-relaxation, recombination of neutral and charged components and quenching of electronically excited molecules is the main mechanism of gas temperature increase in non- equilibrium plasma. VT relaxation and recombination are rather slow and can last tens of microseconds or longer even at atmospheric pressure, which is comparable with the typical gas dynamic times within a scale of several millimeters. Energy release into translational degrees of freedom, during excitation of electronically excited states and molecular dissociation and ionization by electron impact, is a much faster process. For instance, a molecule being excited by electron impact to a repulsive state dissociates to products with high translational energy. The time of thermalization of such "hot" atoms and radicals usually reaches units of nanoseconds. Quenching of electronically excited molecules and electron-ion and ion-ion recombination proceed almost at the same time scale and also lead to "hot" atoms and radicals formation. Such a heating mechanism can become a governing process and produce fast gas heating in the discharge region under high values of reduced electric field $\mathrm{E} / \mathrm{n}$ (close to or higher than the breakdown threshold) [Popov 2001, Aleksandrov et al, 2010a,2010b].

Presently, most researchers applying plasma actuator for flow control propose to use this device to accelerate the flow in the boundary layer near the airfoil surface in the region of flow separation. They consider induced velocity to be one of the main features developed by the actuator in the discharge zone. The gas flow velocity can be changed during the interaction between the electric field and uncompensated spatial plasma charge.

The flow acceleration mechanism is connected with loss of quasi-neutrality in the plasma which conducts electric current. In the case of a small Debye radius, the existence of the electric field feeding the current is always connected with the existence of considerable uncompensated spatial charge in plasma (in the absence of the media polarization $\left.\operatorname{div}\left(\varepsilon_{0} \mathrm{E}\right)=4 \pi \sigma\right)$ ). Gaining the momentum from the electric field, uncompensated charge causes whole gas motion [Sigmond\&Lagstadt, 1993]. For instance, this pattern is typical for glow discharge.

At low ionization degree and high electron energy, the Debye radius is noticeably bigger than the typical size of the plasma region; and then, the electric field is determined only by external conditions, which leads to charged particles acceleration in the external field. The total gas acceleration is determined by the space charge of the plasma region. This charge is formed by the discharge current from the electrodes. A low-current corona discharge from the point-like electrode may be an example of such a situation.

Both gas acceleration in the boundary layer and pulse heating with further expansion may, on the whole, lead to changes of flow characteristics. It is necessary to analyze the value of gas acceleration by discharge as well as gas heating and induced flow in the discharge afterglow in order to investigate the physics of interaction between the nanosecond pulsed discharge and gas flow.

Two different mechanisms, stationary and non-stationary, lead to such interaction. In a stationary case the electrical field is limited by breakdown threshold. In the paper [Likhansky et al, 2010] the estimations based on the volumetric force equation $F=e \times n \times E$ and the Poisson equation lead to simple relation for induced velocity

$$
\mathrm{v}_{\mathrm{g}}=\mathrm{E}^{*}\left(\varepsilon_{\mathrm{i}} / \rho\right)^{1 / 2}
$$

where $\rho$ is the gas density, $\mathrm{E}$ is an applied electric field and $\varepsilon_{i}$ is the ion mobility. This equation describes the gas flow in stationary discharges using the condition that $\mathrm{E}$ cannot 
exceed the breakdown threshold. For free space this equation predicts the maximum induced velocity up to $80 \mathrm{~m} / \mathrm{s}$, but close to the surface due to the viscous effects this maximum cannot be achieved [Likhansky et al, 2010] and actual limit was estimated $\sim 20$ $\mathrm{m} / \mathrm{s}$. Actually, the estimation proposed in [Likhansky et al, 2010] assumes the permanent presence of a spatial charge in the plasma region. In a weak electrical field under consideration this charge cannot be generated by gas ionization or emission from the electrodes [Raizer, 1991]. Thus the estimation [Likhansky et al, 2010] is an upper estimation of the induced velocity in the presence of external source of uncompensated charge in plasma region.

As a rule, the presence of high uncompensated spatial charges in gas is associated with the presence of strong electric field gradients and ionization waves [Starikovskaia et al, 2002]. A streamer discharge is an example of such a case. Uncompensated charge on the ionization wave front at the streamer is under the influence of the strong electric field of the streamer's head. This results in significant acceleration of the gas in the region of the strong field. This process lasts only fractions of nanoseconds. The calculations presented in [Opaits et al, 2005] have shown that the gas velocity in a single streamer's channel may reach units of centimeters per second. This mechanism is implemented in pulsed non-stationary discharges without bias.

AC discharges and pulsed discharges with significant bias situated in between of these two limiting cases. Presently, the possibility of gas acceleration reaching a velocity up to nearly $10 \mathrm{~m} / \mathrm{s}$ has been shown with the help of positive corona [Loiseau et al, 2002; Zouzou et al, 2006; Rickard et al, 2006].

It should be noted that the nature of gas acceleration is the same in all cases. The interaction between the uncompensated plasma charge and the electric field, together with the effective momentum transfer from charged to neutral gas components, generate flux acceleration as a whole.

\subsection{Laminar-turbulent transition control}

In [Grundmann\&Tropea, 2007] artificially excited Tollmien-Schlichting (TS) waves were cancelled using plasma actuators operated in pulsed mode. In order to achieve this a vibrating surface driven by an electromagnetic turbulator was flush mounted in a flat plate to excite the TS waves. These were amplified by an adverse pressure gradient induced by an insert on the upper wall of the test section. A control plasma actuator positioned downstream of the excitation actuator attenuates the waves by imparting an unsteady force into the boundary layer to counteract the oscillation. As a result the amplitude of the velocity fluctuations at the excitation frequency is reduced significantly depending on the distance from the wall. A parameter study was performed to identify the influence of several operation parameters of the control actuator.

The investigations have been performed in an open circuit wind tunnel with a test section of a cross section of $0.45 \mathrm{~m}$ by $0.45 \mathrm{~m}$ and a length of $2 \mathrm{~m}$. An insert on the roof of the test section creates an adverse pressure gradient of $25 \mathrm{pa} / \mathrm{m}$ to promote transition on the flat plate at the relatively low velocity of $9.6 \mathrm{~m} / \mathrm{s}$ measured in the smallest cross section. The boundary-layer thickness has a value of $\mathrm{d}_{99}=5 \mathrm{~mm}$ at $\mathrm{x}=590 \mathrm{~mm}$ yielding a Reynolds number of $\operatorname{Re}=1100$ based on the displacement thickness [Grundmann\&Tropea, 2007]. Figure 31a shows the test section and Fig. 31b shows a closeup view of the two actuators and the measurement position. 
(a)

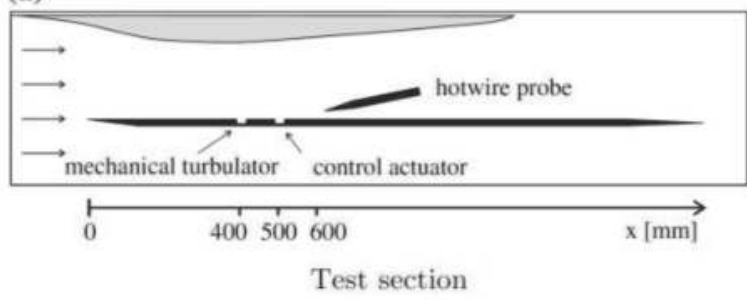

(b)

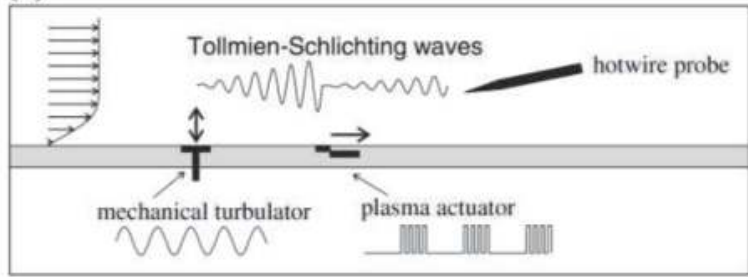

Details of the actuator placement

Fig. 31. Test section and detail view (a) Test section (b) Details of the actuator placement [Grundmann\&Tropea, 2007].

Figure 32 gives more detailed information about the frequency content and the shape of the fluctuations with and without control. The figures on the left show the power spectra densities of the velocity fluctuations and the figures on the right show the time traces of these measurements. With the control actuator working, the amplitude (bottom of Fig. 32a) of the fundamental frequency is reduced significantly, while the modes $f_{2}$ and $f_{3}$ remain unchanged. The mode $f_{4}$ is cancelled while $f_{5}$ disappears below the background noise floor produced by the actuator.
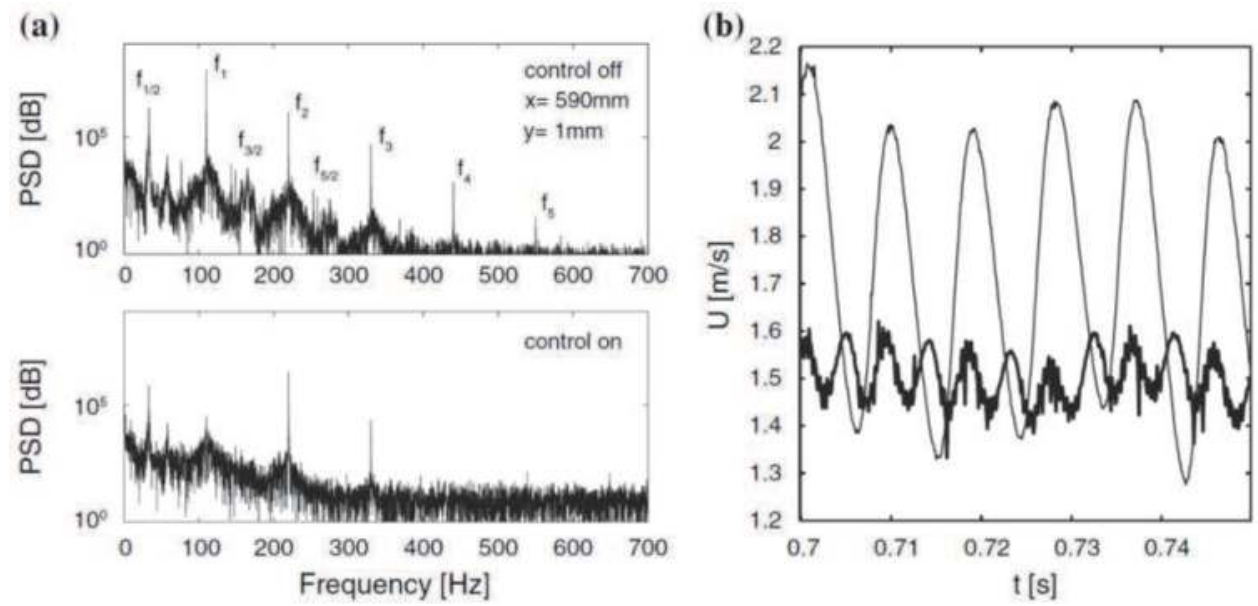

Fig. 32. Power spectra density and time traces with (thick lines) and without (thin lines) cancellation at $x=590 \mathrm{~mm}$. $y=1 \mathrm{~mm}$ [Grundmann\&Tropea, 2007]. 


\subsection{Boundary layer separation control by ionic wind}

Unlike cases involving strong shock waves, a great number of papers on slow subsonic flow control point out the role of plasma effects (and ion wind in particular) in accelerating gas in the boundary layer, controlling the layer detachment and guiding the laminar-turbulent transition [Moreau, 2007].

Any surface-proximal plasma layer employed to change the flow regime can be easily generated by various techniques. For example, papers [Velkoff\& Ketchman 1968; Yabe et al, 1978] and more recent publications [Leger et al, 2001a,2001b] used a direct current discharge with electrodes placed above or on the surface of the airfoil to achieve the effect. A discharge-generated ion wind can provide flow acceleration up to $3-10 \mathrm{~m} / \mathrm{s}$ in the boundary layer [Moreau et al, 2005; Richard et al, 2006].

Prof. Roth and his team [Roth et al, 1998a,1998b,2000] presented another approach to generate the plasma layer near the surface to control flow. This approach is based on creating surface DBD by applying AC sinusoidal voltage. Discharge is developing in the form of thin streamers propagating along the surface above the covered low electrode [Allegraud et al, 2007].

This type of plasma actuator and its modifications have been widely investigated recently [Moreau, 2007]. Paper [Gregory et al, 2007] demonstrates the value of thrust force generated by an asymmetric actuator at the level of $0.2 \mathrm{mN} / \mathrm{W}$. Practically the same value $(0.3 \mathrm{mN} / \mathrm{W})$ was obtained in [Abe et al, 2007]. The flow velocity generated by such an actuator may reach values up to $5 \mathrm{~m} / \mathrm{s}$ according to the measurements presented in [Roth et al, 2006]. Meanwhile, paper [Forte et al, 2006] presented values of induced velocities up to $8 \mathrm{~m} / \mathrm{s}$. Such flow acceleration provides effective control of the velocity profile in the boundary layer as well as its detachment for main flow velocities reaching the value of several dozen meters per second.

For example, in paper [Do et al, 2007], the flow speed ranges from $10 \mathrm{~m} / \mathrm{s}$ to $25 \mathrm{~m} / \mathrm{s}$ and the corresponding Re numbers are from $5 \cdot 10^{4}$ to $5 \cdot 10^{5}$. In this flow regime, the separation point behind the bluff body can be moved downstream in the presence of the AC DBD. However, the separation delay effect is found to decrease as the flow speed increases. Paper [Lopera et al, 2007] described wind tunnel experiments conducted on a 470-sweep, scaled 1303 UAV model for flight control at low angles of attack. The actuators produced significant shifts in the lift curve, up to $25 \%$ for the most effective ramp angles of 20 and 30 degrees, in the $0-20$ degree alpha range for a free-stream velocity of $15 \mathrm{~m} / \mathrm{s}$. For all ramp cases examined, the unsteady (pulsed) actuator was more effective than the steady actuator in controlling flow separation and influencing the aerodynamic lift.

In the study Post et. al. [Post et al, 2007], the effectiveness of a plasma actuator was tested on a high-speed, natural laminar flow, HSNLF(1)-0213 airfoil. The 10-kV peak-to-peak actuator is designed to simulate an aileron-up or trailing-edge flap upward deflection at $M=0.1(\operatorname{Re}=292 \mathrm{~K})$ and $\mathrm{M}=0.2(\mathrm{Re}=584 \mathrm{~K})$. The tests are performed at various angles of attack from $\alpha=-2^{0}$ to $16^{0}$. The results at $M=0.2$ indicate a $2 \%$ increase in $C_{L}$ and up to an $8 \%$ increase in $C_{D}$.

Thus, the plasma actuators based on AC sinusoidal voltage surface dielectric barrier discharges make it possible to change the flow velocity within several meters per second (maximum induced velocity has been reported by Corke [Corke, 2011] V $\sim 12 \mathrm{~m} / \mathrm{s}$ ) and manage the boundary layer detaching at the main flow velocities up to $\sim 40 \mathrm{~m} / \mathrm{s}$. There are no published data on the influence of ionic wind flow acceleration for free stream velocities above $60 \mathrm{~m} / \mathrm{s}$. This result confirms the conclusion of very first paper by Mhitaryan [Mhitaryan et al, 1964] where the authors made a conclusion that the actuator affects the flow through ionic wind mechanism when induced velocity was in the order of $20-25 \%$ from the velocity of free stream. 
A primary goal of the study [Thomas et al, 2009] is the improvement of actuator authority for flow control applications at higher Reynolds numbers. The study examines the effects of dielectric material and thickness, applied voltage amplitude and frequency, voltage waveform, exposed electrode geometry, covered electrode width, and multiple actuator arrays. The metric used to evaluate the performance of the actuator in each case is the measured actuator-induced thrust which is proportional to the total body force. It is demonstrated that actuators constructed with thick dielectric material of low dielectric constant produce a body force that is an order of magnitude larger than that obtained by the Kapton-based actuators used in many previous plasma flow control studies. They achieve jet velocity $5-6 \mathrm{~m} / \mathrm{s}$ at the distance $\sim 4-5 \mathrm{~cm}$ downstream of the actuator (Figure 33).

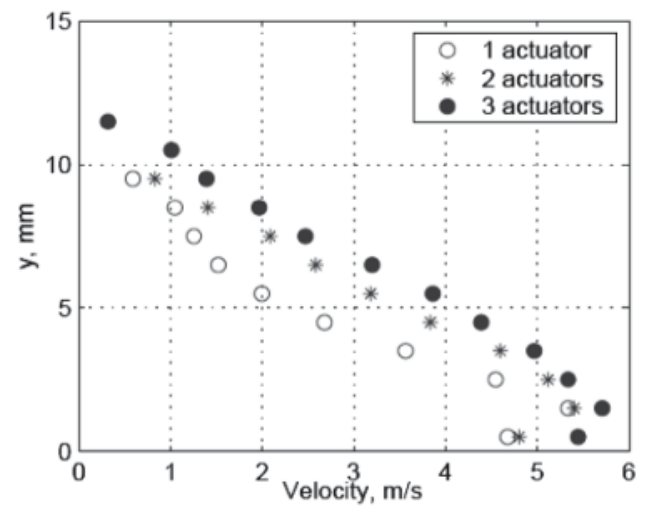

a)

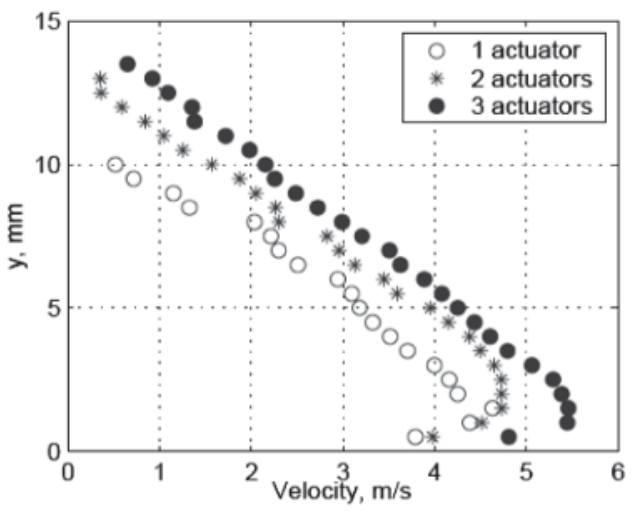

b)

Fig. 33. Mean velocity profiles for single, dual, and triple actuator configurations: a) $3.81 \mathrm{~cm}$ downstream; b) $5.08 \mathrm{~cm}$ downstream [Thomas et al, 2009].

Combined analysis of the capacitance, light emission, size of the plasma region, force production and power consumption is presented in [Kriegseis et al, 2011]. A force-power diagram in presented in Figure 34. Such a plot led to the dimensioned coefficient of the force production efficiency

$$
\eta=\frac{F}{P_{a}}=\frac{F / L}{P_{a} / L}
$$

Measurements [Kriegseis et al, 2011] show that for thrust generation by AC plasma actuator $\eta=2.5 \times 10^{-4} \mathrm{~N} / \mathrm{W}$. The same parameter calculated for Pratt \& Whitney F100 Engine gives $\eta=1.1 \times 10^{-3} \mathrm{~N} / \mathrm{W}$ (calculated from total fuel energy). Thus even assuming no losses for electric power generation, plasma actuator is about order of magnitude less efficient than GTE. The main advantage of plasma actuators is their flexibility and fast response.

It seems that the physical restrictions employed in the mechanism of creating "an ion wind" do not allow significant improvement in performance of this technology because of physical limitations for flow acceleration in the discharge. At the same time, subsonic aerodynamics researchers are very interested in the velocity range from $100 \mathrm{~m} / \mathrm{s}$ (take-off and landing velocities) to $250 \mathrm{~m} / \mathrm{s}$ (cruising speed). Thus, advancing into the region of higher velocities is of great importance and urgency. 


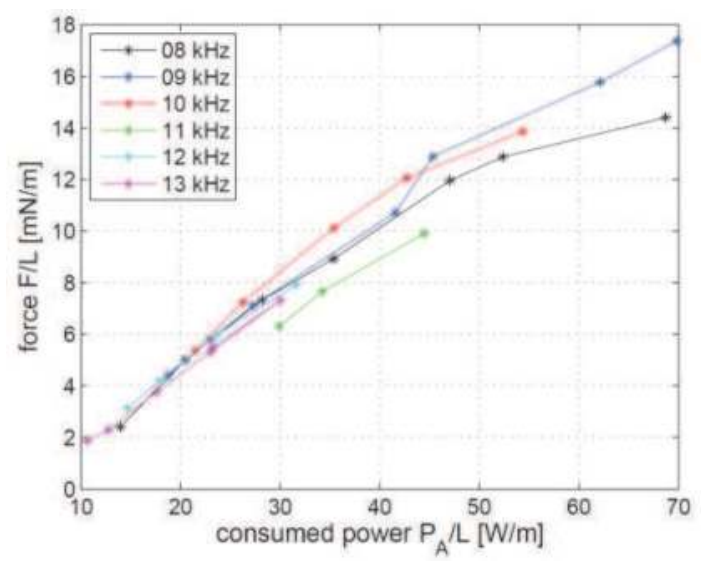

Fig. 34. Dimensioned coefficient of force production efficiency for AC plasma actuator [Kriegseis et al, 2011].

\subsection{Boundary layer separation control by heat release}

Paper [Opaits et al, 2005] proposed using pulsed nanosecond discharge for plasma actuator. The $E / n$ value for this type of the discharge can exceed by several times the breakdown threshold. The high value of the reduced electric field seems to be an evident advantage of such a discharge. Such characteristics as relatively low energy consumption, the possibility of using such discharges within a wide range of pressures, flow velocities, and gas compositions, including high humidity, also contribute to the advantages of the approach proposed. The first experiments [Opaits et al, 2005] have shown that it is possible to firmly control the boundary layer separation using this nanosecond pulsed discharge at velocities up to $75 \mathrm{~m} / \mathrm{s}$ and energy consumption lower than $1 \mathrm{~W} / \mathrm{cm}$ of wingspan.

Further, the impact of pulsed sliding discharge on the flow separation has been investigated in [Roupassov et al, 2006]. The high efficiency of pulsed discharge was shown for the velocity up to $110 \mathrm{~m} / \mathrm{s}$. The main mechanism of plasma influence was concluded to be the boundary layer turbulization, rather than the gas acceleration. An optimum pulsed actuator frequency was found to maximize the actuator effect on lift and drag force and flow reattachment, such as $f_{\text {opt }}=U_{0} / L$, where $U_{0}$ is the main flow velocity and $L$ is the typical distance along the surface to the separation zone. Later, this result was confirmed by Patel et al. [Patel et al, 2007] in experiments for chord Reynolds numbers up to $10^{6}$ and a maximum free-stream speed of $60 \mathrm{~m} / \mathrm{s}$.

Scaling effects of an aerodynamic nanosecond pulsed plasma actuator were investigated in [Sidorenko et al, 2007; Maslov et al, 2007]. Separation control experiments on a rectangular wing (dimensions $0.5 \times 1 \mathrm{~m}^{2}$ ) were carried out using a dielectric barrier discharge plasma at subsonic speed for chord Reynolds numbers from 0.35 to $0.875 \cdot 10^{6}$. Surface pressure measurements and flow visualization show that global flow separation on the wing can be mitigated or eliminated by the plasma actuators (Figure 35). The data were obtained for a wide range of attack angles, flow speeds, plasma excitation frequencies and power. New applications of several kinds of voltage pulses for plasma excitation were discussed, including microsecond and nanosecond pulses. As in [Roupassov et al, 2006], it was found there that control efficiency strongly depends on discharge frequency (Figure 36). 

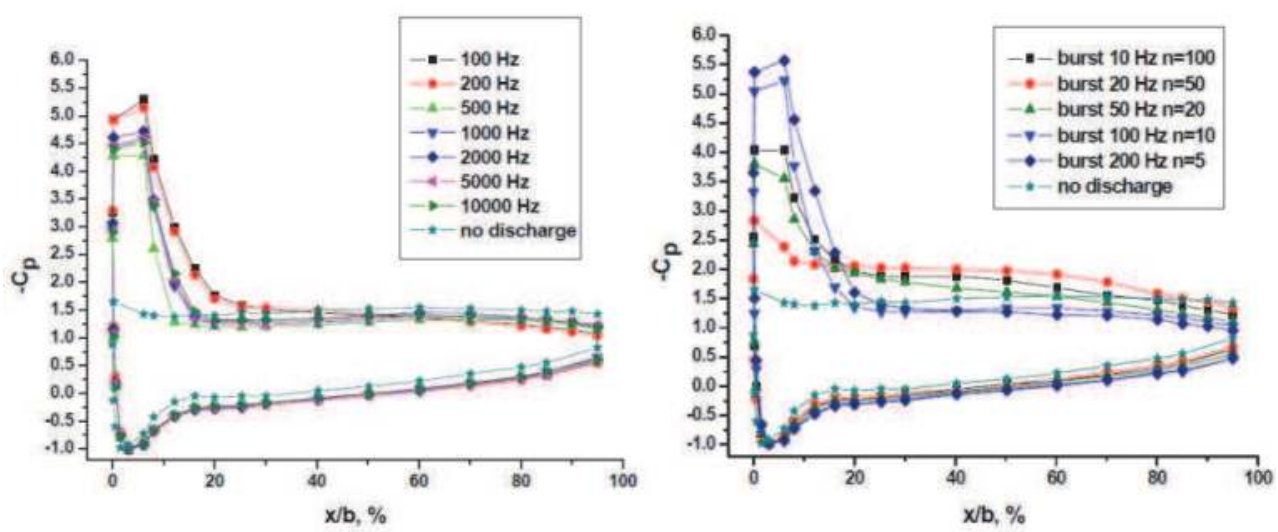

Fig. 35. $C_{p}$ distribution along the model chord $\left(\alpha=190 ; U^{\infty}=19 \mathrm{~m} / \mathrm{s} ; V=24 \mathrm{kV}\right.$; $\left.\operatorname{Re}=0.8 \times 10^{6}\right)$ [Sidorenko et al, 2007]
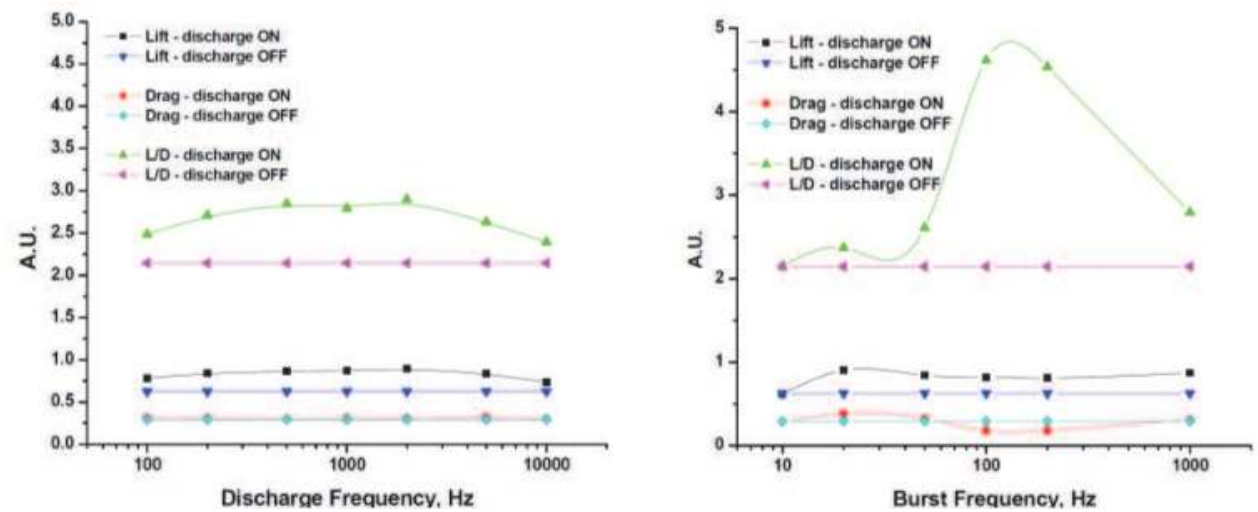

Fig. 36. Lift, Drag force and Lift-to-Drag ratio in dependence on the frequency. $\alpha=22^{0} ; U^{\infty}=17.4 \mathrm{~m} / \mathrm{s} ;$ a) - Periodic Mode, $P=2.5-250 \mathrm{~W}$ for $f=100-10000 \mathrm{~Hz}$, respectively; $b$ ) - Burst Mode, $P=25 \mathrm{~W}$ for all regimes [Sidorenko et al, 2007].

Separation control experiments on a rectangular wing were carried out using nanosecond dielectric barrier discharge plasma at subsonic speed $(\mathrm{M}=0.3-0.75)$ for chord Reynolds numbers between 0.5 and $2 \cdot 10^{6}$ [Roupassov et al, 2007]. This work has demonstrated the possibility to control the flow at cruising velocity with a plasma actuator. A vacuum blowdown wind tunnel has been used for the experiments. The system was modernized to perform the experiments in pulse regime. The nozzle with working chamber operates at Mach numbers from $\mathrm{M}=0.6$ to $\mathrm{M}=0.9$. Figure 37 depicts the installation. 


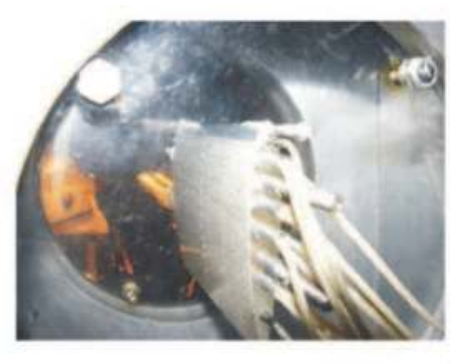

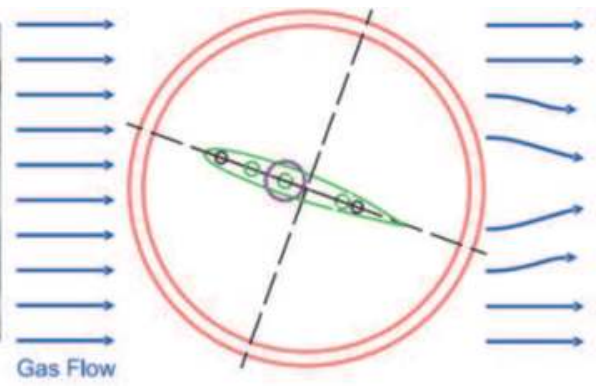

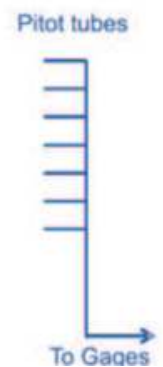

Fig. 37. Photo of the model and schematics of pressure measurements. Pressure distribution have been measured in the wake of model and on the model surface [Roupassov et al, 2007].

The discharge impact on the flow pattern near the surface has been investigated. The Mach number was equal to $\mathrm{M}=0.65-0.6$; $0.7-0.65$; or $0.74-0.69$ in different experiments. The discharge frequency in the experiments was equal to $5 \mathrm{kHz}$. High-voltage pulses have amplitude of $25 \mathrm{kV}$, pulse width was $12 \mathrm{~ns}$. Discharge energy was equal to $10 \mathrm{~mJ} /$ pulse. The plasma impact was investigated for angles of attack between 0 and $30^{\circ}$.

An unseparated flow regime with local supersonic zone and shock wave formation was observed for small angles of attack. These regimes were clearly identified by the pressure jump in the middle of the airfoil surface. This jump is associated with the shock wave location (Fig. 38). The discharge impact for angles within the range of $0-15^{0}$ is negligible. For higher angles of attack, the flow separation is observed and the pattern of pressure distribution changes (Fig. 38). For angles of attack higher than the stall angle, the discharge switches the flow to the unseparated flow regime. Figure 38, a presents the pressure distribution on the upper surface of the model. The X-value corresponds to the distance from the leading edge of the model to the pressure port. The discharge was able to remove high-frequency pulsations in the wake of the model. The data from the pressure gauges for Mach number $\mathrm{M}=0.7$ are presented in Fig. $38, \mathrm{~b}$ to illustrate the noise reduction. Gauge N1 records the pressure at the upper surface of the model and shows the change in the attack angle. Gauges N2-4 are placed in the wake of the model. Pressure pulsations in the wake disappear when the discharge is switched on. This effect was observed at high angles of attack (starting with $\alpha=24^{\circ}$ ) for Mach number $M=0.65-0.75$. The mean pressure value near the model surface does not change significantly, while high-frequency pulsation amplitude decreases dramatically. Thus, the study of separation control for the model of C-141 airfoil has been carried out at transonic velocities $(\mathrm{M}=0.65-0.75)$. Dielectric barrier discharge plasma was used for separation control. The effects of the angle of attack and flow Mach number on the efficiency of flow control were studied in experiments. Nonequilibrium plasma impact was observed for angles of attack from $18^{0}$ to $30^{\circ}$.

The discharge removes both flow separation and high-frequency pulsations in the wake. These experiments demonstrate a possibility of transonic flow separation control using lowenergy pulsed nanosecond surface dielectric discharges.

Thus, nanosecond pulsed discharges have demonstrated an extremely high efficiency of operation for aerodynamic plasma actuators over a very wide velocity $(\mathrm{M}=0.03-0.75)$ and Reynolds number $\left(\operatorname{Re}=10^{4}-2 \times 10^{6}\right)$ range. For further technological development, it is extremely important to understand the physics of the nanosecond plasma actuator and differences between different types of SDBD in terms of their efficiencies [Roupassov et al, 2008a,2008b,2009; Nikipelov et al, 2009; Correale et al, 2011; Rios et al, 2011]. 

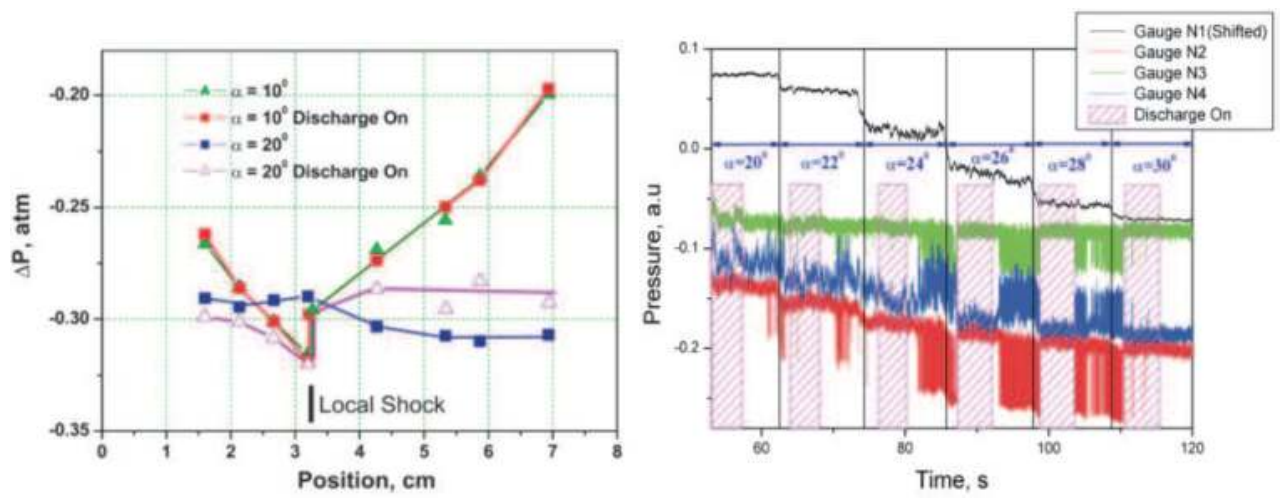

Fig. 38. a) Pressure distribution on model surface with and without discharge.

Mach number $M=0.74$. Total pressure $P=1 \mathrm{~atm}$. b) Noise reduction in the wake of the model. Mach number $\mathrm{M}=0.7$. Total pressure $\mathrm{P}=1 \mathrm{~atm}$

[Roupassov et al, 2007].

From this point of view there are several important milestones. Paper [Roupassov et al, 2006] experimentally demonstrated that the pulsed nanosecond high-voltage discharge used for boundary layer separation control in a wide range of free stream velocity produces no gas acceleration. In [Visbal\&Gaitonde, 2006] the use of a steady counter-flow DBD actuator as a boundary-layer tripping device was numerically analyzed. According to calculations, the actuator induced transition and turbulence, and generates a fuller velocity profile. This feature was exploited to delay stall of a NACA 0015 airfoil at high angle of attack using a pulsed counter-flow actuator. Thus, [Visbal\&Gaitonde, 2006] demonstrated that the co-flow gas acceleration is not necessary for boundary layer control. In [Roupassov et al, 2008a] the mechanism of pulsed nanosecond high-voltage discharge influence on boundary layer separation was experimentally demonstrated. It was shown that fast nonequilibrium plasma thermalization (on the time scale of hundreds of nanoseconds) produces hot, overpressurized gas layer in the discharge zone, followed by strong shock wave formation. It was suggested that the shock wave propagation across the boundary layer causes strong flow perturbations and provokes flow re-attachment through formation of large scale vortices in the shear layer separating free stream and separation bubble [Roupassov et al, 2008a]. Later, experimental results [Samimy et al, 2010] prove that nanosecond SDBD plasma performs as an active trip at pre-stall angles of attack and provides high amplitude perturbations that manipulate flow instabilities and generate coherent spanwise vortices at post-stall angles. These coherent structures entrain freestream momentum thereby reattaching the normally separated flow to the suction surface of the airfoil. Numerical modeling of SDBD development also shows fast formation of plasma layer and shock wave generation [Unfer\&Boeuf, 2009; Starikovskii et al, 2009].

The process of nanosecond pulsed plasma layer interaction with the flow, formation of perturbations and vortices, and flow re-attachment was investigated in details in [Correale et al, 2011].

A model of NACA 63-618 airfoil with the chord of $20 \mathrm{~cm}$ and span of $40 \mathrm{~cm}$ with the actuator applied was used for experiments. Several different actuators were used, including single, double and triple ones. The flow speed was 30 m/s. Some results are shown in Figure 39. 
The shock wave generated by actuators can be clearly seen, as well as large scale vortex structure as it developed 40 microseconds after the discharge [Correale et al, 2011]. It was observed that after 2-3 discharges the flow pattern changed completely. Flow reattached, separation zone shifted downstream. It was found that placing second actuator into the point to where separation was shifted by the first actuator, shifts the separation further downstream. This allows to achieve attached flow up to AoA $=32^{0}$, using three pairs of the actuators. Summary energy consumption was less than $1 \mathrm{~W}$ for $40 \times 20 \mathrm{~cm}$ airfoil in $30 \mathrm{~m} / \mathrm{s}$ flow.

Thus typical system reaction time was $10-15 \mathrm{~ms}$ and was close to the time of the vortex propagation along the surface of the airfoil (Figure 39). From Figure 39 it is clear that perturbation generated by pulsed actuator initiates instability in the shear layer. This instability propagates along the shear layer; additional mixing brings additional momentum into boundary layer from the main stream and attaches the flow. It should be noted that the discharge energy plays a secondary role: two different regimes (repetitive pulse mode and burst mode) shown in the columns 1 and 2, correspondingly, demonstrate almost the same dynamics of flow attachment while the discharge energy in the second case is 10 times bigger. This means that we need high rate of energy release from discharge to translational degrees of freedom of gas. Fast transition (in time scale shorter than gas-dynamic time in plasma layer) means the efficient generation of the shock wave and efficient excitation of perturbations in the flow [Starikovskiy et al, 2009]. That is why the kinetics of energy transfer in nonequilibrium plasma is the most critical issue for pulsed SDBD actuators.

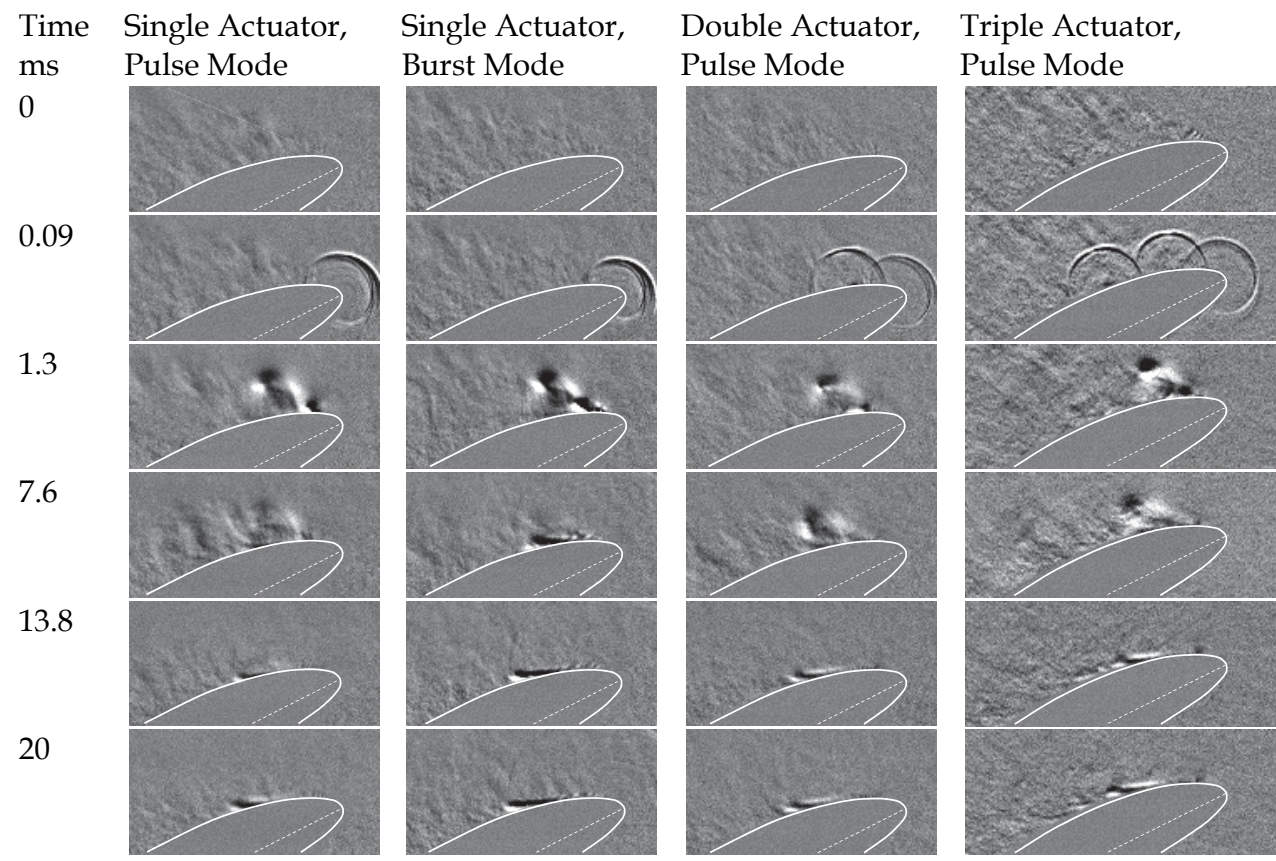

Fig. 39. Dynamics of boundary layer re-attachment. $V=30 \mathrm{~m} / \mathrm{s}, \mathrm{AoA}=26^{0}, \mathrm{NACA} 63-618$ airfoil, chord length was $20 \mathrm{~cm}$ wing span was $40 \mathrm{~cm}$. Discharge energy $5 \mathrm{~mJ} / \mathrm{pulse}$, discharge frequency $200 \mathrm{~Hz}$ in pulse and burst modes; 10 pulses per burst; $\mathrm{d} \tau=100 \mu \mathrm{s}$ [Correale et al, 2011]. 
As it was indicated above, the main mechanism of pulsed nanosecond SDBD effect on the flow is an extremely fast gas heating. Energy release in the gas is sometimes considered to be $Q=U \times I \times \tau$, whereas gas heating is defined by $\Delta T=Q / C_{p}$. Such an estimate includes some strong assumptions. The electric field energy is supposed to be completely absorbed by gas. This is not always true in the case of strong electric fields, since part of the energy is lost in radiation processes. In the case of high-current discharges at low electric fields, some energy will be lost in the near-electrode regions. In this case, part of the energy goes to heat the electrodes. Thus, the current multiplied by voltage in the discharge gap gives only the upper estimation of energy release. Estimations of temperature changes in the discharge are stillstronger suppositions. The equation $\Delta T=Q / C_{p}$ is completely valid for the thermal equilibrium state when internal degrees of freedom of the gas are in equilibrium with the translational degrees of freedom. That is not the case under conditions of strongly nonequilibrium plasma of gas discharge. On the other hand, using specific heat under constant pressure $C_{p}$ presumes that energy release occurs at times noticeably higher than gasdynamics times. Then, it is quite reasonable to use the supposition $P=$ const.

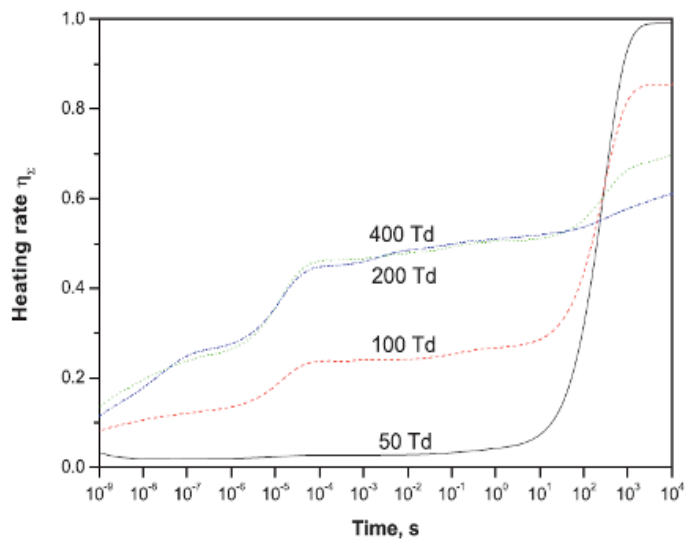

Fig. 40. Percentage of nonequilibrium energy transferred into translational degrees of freedom [Flitti\&Pancheshnyi, 2009].

So, when analyzing the thermal mechanism of plasma actuator impact on the flow, it is necessary to take into account not only radiation energy loss, wall heating, etc., but also the rate of energy relaxation as compared to the typical times of plasma layer expansion.

Dynamics of plasma relaxation in the case of excitation by low and moderate electrical fields was calculated many times (see, for example, [Flitti\&Pancheshnyi, 2009], Figure 40).

Mechanisms of fast gas heating under low electrical fields $(\mathrm{E} / \mathrm{N}<20 \mathrm{Td})$ mainly include elastic electrons scattering and rotational excitation of the molecules. Here, typical relaxation time is rather short because of fast energy exchange between rotational and translational degrees of freedom, but total energy fraction of this excitation is very small (Figure 41). According to this Figure, under moderate electrical fields $(E / N=20-200 \mathrm{Td})$ there is efficient excitation of vibrational and electronic degrees of freedom. VT relaxation under low temperature conditions is very slow process and curve "50 Td" in Figure 40 demonstrates that almost all the energy will be frozen for about $100 \mathrm{sec}$ before real gas heating will take place. Under such conditions formation of a shock wave (strong perturbations) is impossible. Instead, weak 
compression waves will appear. Under higher E/N (100-200 Td) efficient excitation of electronic degrees of freedom and molecules dissociation will take place (Figure 41.) Dissociation by e-impact takes place through repulsive states and $20-30 \%$ energy goes immediately to translational motion of fragments (for example, e $+\mathrm{O}_{2} \rightarrow \mathrm{e}+2 \mathrm{O}+\Delta \mathrm{E}$ ). Collisional quenching of electronically excited states (in air there are nitrogen triplets $-\mathrm{N}_{2}(\mathrm{~A}$, $\left.\mathrm{B}, \mathrm{C}, \mathrm{a}^{\prime}, \ldots\right)$ ) also lead to energy release into translational degrees of freedom:

$$
\begin{gathered}
\mathrm{e}+\mathrm{N}_{2} \rightarrow \mathrm{e}+\mathrm{N}_{2}{ }^{*}\left(\mathrm{~A}, \mathrm{~B}, \mathrm{C}, \mathrm{a}^{\prime}, \ldots\right) \\
\mathrm{N}_{2}^{*}\left(\mathrm{~A}, \mathrm{~B}, \mathrm{C}, \mathrm{a}^{\prime}, \ldots\right)+\mathrm{O}_{2} \rightarrow \mathrm{N}_{2}+2 \mathrm{O}+\Delta \mathrm{E} \\
\mathrm{O}\left({ }^{1} \mathrm{D}\right)+\mathrm{N}_{2} \rightarrow \mathrm{O}+\mathrm{N}_{2}+\Delta \mathrm{E}
\end{gathered}
$$

This mechanism was proposed for air in [Popov, 2001].

In SDBDs reduced electrical field reaches extremely high value $(\mathrm{E} / \mathrm{n} \sim 800-1200 \mathrm{Td})$. Significant part of the electrons energy goes to gas ionization. Extension of the energy relaxation mechanism to high $\mathrm{E} / \mathrm{n}$ was proposed in [Aleksandrov et al, 2010]. We have analyzed the results of two observations of nonequilibrium plasma produced by highvoltage nanosecond discharges. These results involved the measurement of the velocity of a shock wave that propagates through air heated by an impulse discharge at 20 Torr and the experimental study of a SDBD in atmospheric-pressure air. The electron power transferred into heat in air plasmas was estimated in high $\left(\sim 10^{3} \mathrm{Td}\right)$ electric fields. It is shown that around $50 \%$ of the discharge power can be transferred into heat for a short period of time ( $1 \mu \mathrm{s}$ at atmospheric pressure). This effect is much more profound than that observed at low and moderate reduced electric fields.

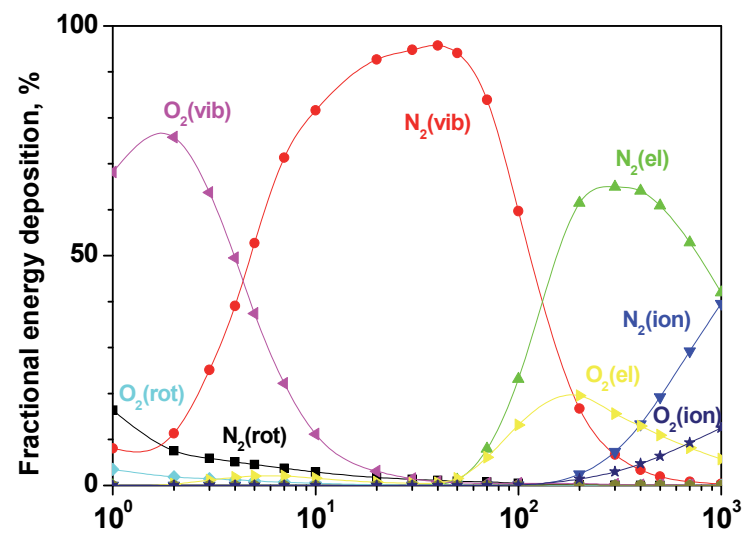

Fig. 41. Discharge energy distribution across internal degrees of freedom in air [Aleksandrov et al, 1982].

A kinetic model was suggested to simulate the fast heating of air plasmas under the conditions considered. This model extends work previously developed for describing fast heating in moderate $\left(<10^{2} \mathrm{Td}\right)$ reduced electric fields and takes into account electron-impact excitation of high-energy states followed by their collisional quenching, as well as ion-molecule reactions and electron-ion and ion-ion recombinations. These reactions play an important role in 
plasmas produced at high electric fields when most electron energy losses are due to electronimpact ionization. Based on this model, the fractional electron power transferred into heat was calculated as a function of the reduced electric field in dry and humid air at various pressures. Calculations agree well with the results of experimental analysis of SDBD at atmospheric pressure. There is also reasonable agreement between theory and measurements in the impulse high-voltage nanosecond discharge initiated in air at 20 Torr.

According to the calculation at 20 Torr, approximately equal parts $(<10 \%)$ of the electron power are converted into heat: (i) through electron impact dissociation of $\mathrm{O}_{2}$ and excitation of $\mathrm{N}_{2}(A, B, C, a)$ states followed by quenching by $\mathrm{O}_{2}$, which are suggested to describe fast gas heating in air plasmas at moderate electric fields; (ii) through electron-impact excitation of higher electronic $\mathrm{N}_{2}$ states followed by dissociation and quenching by $\mathrm{O}_{2}$ and (iii) through electron-ion recombination. At atmospheric pressure, the calculated total fractional electron power transferred into heat could be increased by $<20 \%$ due to the three-body recombination of positive and negative ions and, to a smaller extent, due to ion-molecule reaction in the discharge afterglow. The calculations shows that, under the conditions considered, the characteristic time of gas heating lies in the range $0.3-5 \mathrm{~ns}$ for $1 \mathrm{~atm}$ and in the range $5-80 \mathrm{~ns}$ for a pressure of 20 Torr (Figure 42 ).

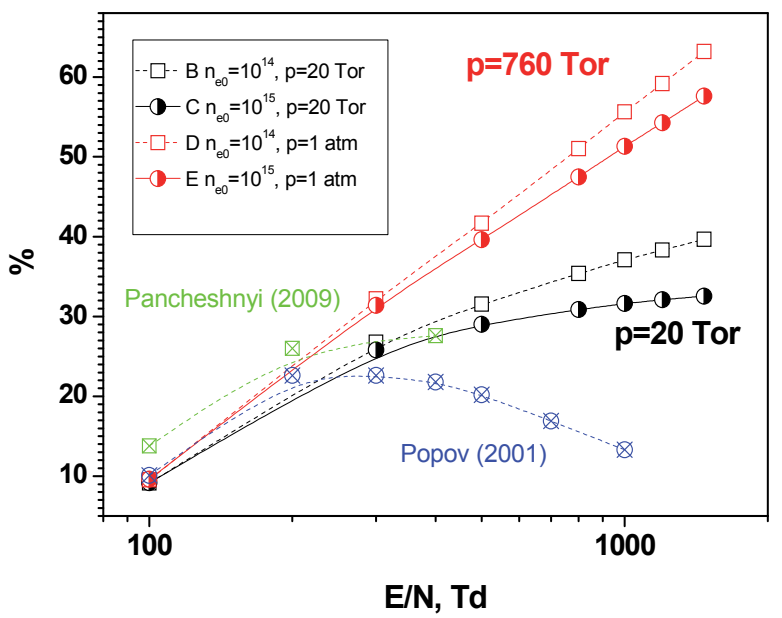

Fig. 42. The total fractional electron power transferred into heat in dry air at 20 Torr and 1 atm as a function of the reduced electric field at which the energy was deposited in a highvoltage nanosecond discharge [Aleksandrov et al, 2010]. The calculations were carried out for $n_{\mathrm{ef}}=10^{15} \mathrm{~cm}^{-3}$ (solid curves) and $10^{14} \mathrm{~cm}^{-3}$ (dash curves). Curve 1 corresponds to calculations [Flitti\&Pancheshnyi, 2009] and curve 2 corresponds to the calculations assuming that $28 \%$ of the energy spent on the excitation of electronic $\mathrm{N}_{2}$ and $\mathrm{O}_{2}$ states is quickly transferred into gas heating [Popov, 2001].

It should be mentioned that both $\mathrm{AC}$ and pulsed discharges always provide a combined excitation. We can generate the flow perturbation with AC BDB (see, for example, [Visbal\& Gaitonde, 2006]) and we can accelerate the gas using pulsed DBD - especially with additional bias [Opaits et al, 2010]. Using one or another discharge type allows to optimize the process and to minimize the energy consumption. 


\section{Conclusions}

Flow control opportunities by plasma include shock wave pattern control; aerodynamic breaking; drag reduction; heat mitigation; flow vectorization, acceleration and deceleration; MHD power extraction and breaking. Boundary layer control could be subdivided into laminar-turbulent transition control; boundary layer separation control; lift and drag force control; acoustic noise control; mixing enhancement. Nonequilibrium plasma also may be very efficient in ignition and flame stabilization control; engine performance enhancement, including possibility of fast initiation of detonation waves.

This review mentions briefly the most important results obtained over the last decade in plasma assisted aerodynamics and discusses the physical mechanisms of the phenomena under consideration. There are three different physical mechanisms which control the efficiency of plasma aerodynamics: 1) gas heating; 2) electrostatic momentum transfer to the gas; 3) magneto-hydrodynamic effects, including MHD flow acceleration and on-board electricity generation using gas flow kinetic energy. It is shown that the most universal mechanism of plasma action on airflows is their local heating. This mechanism is responsible for supersonic flow and shock wave control, can play an important role in MHD flow interaction and is central to boundary layer control by pulsed nanosecond SDBD. It has been demonstrated that the pulsed nanosecond SDBD is promising for boundary layer control at take-off, landing and cruising flow speeds. The modification of boundary layer by ionic wind is important when using discharges of longer duration (for instance, with sinusoidal high-voltage power supply). However, the last achievements in this area are more moderate.

It was shown that the plasma recombination and energy release in the recombination process control the efficiency of plasma-assisted flow control. In the case of "plasma" mechanisms (electrostatic momentum transfer; magneto-hydrodynamic effects) fast plasma recombination and thermalization limits the possibilities of flow control and sometimes make their usage impossible. Vice versa, for methods based on the gas heating plasma recombination is a major source of energy and the fast heat release is the most important factor which increases the efficiency of plasma control.

Recent advances in plasma kinetics allow to build detailed kinetic models to predict the efficiency of different plasma mechanisms in different aerodynamic applications, but most of the progress in nonequilibrium plasma aerodynamics has been made experimentally. Advances in theoretical simulation of the interaction between non-equilibrium plasma and high-speed airflows have been less promising. The main reason is that we have to simulate simultaneously complicated hydrodynamic, electrodynamics and kinetic processes on wide space and time scales. In addition, there is the shortage in information about the mechanisms, rates and products of plasma processes under nonequilibrium conditions. Further study of the mechanisms responsible for plasma - gas flow interaction on various time scales would favour the progress in this area.

\section{Acknowledgements}

The work was partially supported by Russian Foundation for Basic Research under the project "Nonequilibrium plasma thermalization", AFOSR under the project "Fundamental Mechanisms, Predictive Modeling, and Novel Aerospace Applications of Plasma Assisted Combustion", and DOE Combustion Energy Frontiers Research Center. 


\section{References}

Abe,T., Takizawa,Y., Sato,S., Kimura,N. "A Parametric Experimental Study for Momentum Transfer by Plasma Actuator". 45th AIAA Aerospace Sciences Meeting and Exhibit. 8 - 11 January 2007, Reno, Nevada. AIAA 2007-187

Adelgren, R., Elliott, G., Knight, D., Zheltovodov, A., and Beutner, T., “Energy Deposition in Supersonic Flows," AIAA Paper 2001-0885, 2001.

Adelgren, R., Elliott, G., Knight, D., Zheltovodov, A., and Buetner, T., “Localized Flow Control in Supersonic Flows by Pulsed Laser Energy Deposition," The Third Workshop on Magneto- and Plasma Aerodynamics for Aerospace Applications, Inst. for High Temperatures, Moscow, April 2001.

Adelgren, R., “Localized Flow Control with Energy Deposition,” Ph.D. Thesis, Dept. of Mechanical and Aerospace Engineering, Rutgers Univ., Sept. 2002.

Aleksandrov N.L., and Konchakov V. Plasma Physics Reports. 1982

Aleksandrov N.L., Kirpichnikov A.A., Kindusheva S.V., Kosarev I.N., Starikovskii A.Yu. Non-Equilibrium Plasma Life Time Measurements and Flow Control. 45th AIAA Aerospace Sciences Meeting and Exhibit 8 - 11 Jan 2007 Grand Sierra Resort Hotel Reno, Nevada. Paper AIAA-2007-0997

Aleksandrov N.L., Kindusheva S.V., Kirpichnikov A.A., Kosarev I.N., Starikovskaia S.M. and Starikovskii A.Yu. Plasma decay in $\mathrm{N}_{2}, \mathrm{CO}_{2}$ and $\mathrm{H}_{2} \mathrm{O}$ excited by high-voltage nanosecond discharge. J. Phys. D: Appl. Phys. 2007404493

Aleksandrov N.L., Kindusheva S.V., Kosarev I.N. and Starikovskii A.Yu. Plasma decay in air and $\mathrm{N}_{2}: \mathrm{O}_{2}: \mathrm{CO}_{2}$ mixtures at elevated gas temperatures. J. Phys. D: Appl. Phys. 2008. 41 No 21. 215207.

Aleksandrov N., S.Kindusheva, I.Kosarev, A.Starikovskii, Plasma Decay in Air and $\mathrm{N}_{2}: \mathrm{O}_{2}: \mathrm{CO}_{2}$ Mixtures at Elevated Gas Temperatures. AIAA-2009-1048. 47th AIAA Aerospace Sciences Meeting including The New Horizons Forum and Aerospace Exposition, Orlando, Florida, Jan. 5-8, 2009

Aleksandrov N.L., Kindusheva S.V., Nudnova M.M. and Starikovskiy A.Yu. Mechanism of ultra-fast heating in a nonequilibrium weakly-ionized air discharge plasma in high electric fields. J. Phys. D: Appl. Phys. 43 (2010) 255201 (19pp)

Aleksandrov N., Kindusheva S., Nudnova M., Starikovskiy A. Rate of Plasma Thermalization of Pulsed Nanosecond Surface Dielectric Barrier Discharge. 48th AIAA Aerospace Sciences Meeting. Orlando, Florida. Jan 2010. Paper AIAA-20100465

Aleksandrov N.L., Kindusheva S.V., Kirpichnikov A.A., Kosarev I.N., Starikovskaia S.M. and Starikovskii A. Yu. Plasma decay in air excited by high-voltage nanosecond discharge. 10 ${ }^{\text {th }}$ Intern.Workshop on Magneto-Plasma Aerodynamics. March 22-24, 2011. Moscow, Russia

Allegraud,K., Guaitella,O. and Rousseau,A. "Spatio-temporal breakdown in surface DBDs: evidence of collective effect". 2007. J. Phys. D: Appl. Phys. 40 7698-7706

Anokhin E.M., Starikovskaia S.M., Starikovskii A.Yu. Energy transfer in hypersonic plasma flow and flow structure control by low temperature nonequilibrium plasma. 42nd AIAA Aerospace Sciences Meeting and Exhibit 5 - 8 January 2004, Reno, Nevada AIAA 2004-674.

Azarova O., Knight D., Kolesnichenko Y. Characterization of Flowfield Types Initiated by Interaction of Microwave Filament with Supersonic Body 49th AIAA Aerospace Sciences Meeting including the New Horizons Forum and Aerospace Exposition 4 7 January 2011, Orlando, Florida AIAA 2011-1026 
Bletzinger,P., Ganguly,B.N., VanWie,D., and Garscadden,A. "Plasmas in high speed aerodynamics". J. Phys. D: Appl. Phys. 38 (2005) R33-R57

Bobashev S. V., Vasil'eva R. V., Erofeev A. V., Lapushkina T. A., Ponyaev, D. M. Van Wie. "Relaxation of the shock-wave configuration in a diffuser after termination of the action of magnetic and electric fields", Technical Physics Letters, V.32, N2, 2006, p. 106-109.

Collins C.B. Collisional-dissociative recombination of electrons with molecular ions. Phys. Rev. 140 (1965) A1850-575

Corke TC, Enloe CL, and Wilkinson SP. 2010 Plasma actuators for flow control. Annual Review of Fluid Mechanics 42: 505-529, 2010. 11

Corke T.C. Dielectric Barrier Discharge Plasma Actuators. Lecture Series Notes for Von Karman Institute Lectures. 2011.

Correale G., Popov I.B., Rakitin A.E., Starikovskii A.Yu., Hulshoff S.J., Veldhuis L.L.M. Flow Separation Control on Airfoil with Pulsed Nanosecond Discharge Actuator. 49th AIAA Aerospace Sciences Meeting. Orlando, Florida. Jan 2011. Paper AIAA-20111079

Cunningham and Hobson. (1972)

Do,H., Kim,W., Mungal,M.G., Cappelli,M.A. "Bluff Body Flow Separation Control using Surface Dielectric Barrier Discharges". 45th AIAA Aerospace Sciences Meeting and Exhibit 8 - 11 January 2007, Reno, Nevada AIAA 2007-939

Erdem E., Yang L., Kontis K. Drag Reduction Studies by Steady Energy Deposition at Mach 5. 49th AIAA Aerospace Sciences Meeting including the New Horizons Forum and Aerospace Exposition. 4 - 7 January 2011, Orlando, Florida. AIAA 2011-1027.

Erofeev, Lapushkina T., Poniaev S., and Bobashev S. "Supersonic Body Streamline at Different Configuration Gas Discharge", AIAA-2010-1382, 48th AIAA Aerospace Sciences Meeting and Exhibit and 12th Weakly Ionized Gas Workshop, Orlando, Florida, Jan.4-7, 2010.

Flitti O. and Pancheshnyi S., Eur. Phys. J. Appl. Phys. 45, 21001 (2009)

Florescu-Mitchell A.I. and Mitchell J.B.A. Dissociative recombination. Physics Reports. 430. (2006) 277-374

Forte,M., Jolibois,J., Moreau,E., Touchard,G. and Cazalens,M. "Optimization of a dielectric barrier discharge actuator by stationary and instationary measurements of the induced flow velocity, application to airflow control".2006. AIAA Meeting (San Francisco, USA, June 2006) paper 2006-2863

Gregory,J.W., Enloe,C.L., Font,G.I., and McLaughlin,T.E. "Force Production Mechanisms of a Dielectric-Barrier Discharge Plasma Actuator". 45th AIAA Aerospace Sciences Meeting and Exhibit 8 - 11 January 2007, Reno, Nevada. AIAA 2007-185

Griffiths W. J.Aeron.Sci. 1956. V.23. N 1. P.19.

Grundmann S and Tropea C. 2007 Experimental transition delay using glow-discharge plasma actuators. Experimental Fluids 41: 653-657, 2007.

Gurijanov EP and Harsha PT. 1996 AJAX: new directions in hypersonic technology. AIAA1996-4606.

Kalra CS, Zaidi SH, Miles RB, and Machret SO. 2010 Shockwave-turbulent boundary layer interaction control using magnetically-driven surface discharges. Experiments in Fluids DOI 10.1007/s00325-010-0898-9, 2010.

Khorunzhenko V.I., Roupassov D.V., Starikovskii A.Yu. Hypersonic Flow and Shock Wave Structure Control by Low Temperature Nonequilibrium Plasma of Gas Discharge. 38th AIAA/ASME/SAE/ASEE Joint Propulsion Conference \& Exhibition, 2002. Indianapolis, AIAA 2002-2497. 
Khorunzhenko V.I., Roupassov D.V., Starikovskaia S.M., Starikovskii A.Yu. Hypersonic Shock Wave - Low Temperature Nonequilibrium Plasma Interaction. 39th AIAA/ASME/SAE/ASEE Joint Propulsion Conference and Exhibit, 2003. AIAA Paper AIAA 2003-5048.

Klimov,A.I., Koblov,A.N., Mishin,G.I., Serov, Yu.L., and Yavor,I.P. "Shock wave propagation in a glow discharge" 1982 Sov. Tech. Phys. Lett. 8

Knight D. 2008 Survey of aerodynamic drag reduction at high speed by energy deposition. Journal of Propulsion and Power 24: 1153-1167, 2008. 12

Kolesnichenko,Yu.F., Brovkin,V.G., Khmara,D.V., Lashkov,V.A., Mashek,I.Ch. and Ryvkin,M.I. "Fine Structure of MW Discharge: Evolution Scenario". 2004 4th Int. Workshop on Thermochemical and Plasma Processes in Aerodynamics (July 2004)

Kossyi I.A., A.Yu.Kostinsky, A.A.Matveyev and V.P.Silakov. Kinetic scheme of the nonequilibrium discharge in nitrogen-oxygen mixtures. Plasma Source Sci. Technol., 1 (1992) 207-220

Kriegseis J., Moller B., Grundmann S., and Tropea C. Light Emission, Discharge Capacitance and Thrust Production of DBD Plasma Actuators 49th AIAA Aerospace Sciences Meeting including the New Horizons Forum and Aerospace Exposition 4 - 7 January 2011, Orlando, Florida AIAA 2011-155

T.A.Lapushkina, A.V.Erofeev, S.A.Ponyaev, S.V.Bobashev, "Supersonic flow of a nonequilibrium gas-discharge plasma around a body", Technical Physics, V.54, No 6, 2009, P. 840-848.

T.A.Lapushkina, A.V.Erofeev, S.A.Poniaev, S.V.Bobashev. Air supersonic flow control by energy deposition and mhd action near body front part. 49th AIAA Aerospace Sciences Meeting including the New Horizons Forum and Aerospace Exposition 4 7 January 2011, Orlando, Florida AIAA 2011-1025.

Lashin A.M., Starikovskiy A.Yu. Shock and detonation waves interaction with entropy layers. Technical Physics Technical Physics. Springer. 1995. V 65. N.8. C.11-24.

Leger,L., Moreau,E. and Touchard,G. "Control of low velocity airflow along a flat plate with a DC electrical discharge". 2001.Proc. IEEE-IAS World Conf. on Industrial Applications of Electrical Energy (Chicago, USA, 30 September - 4 October)

Leger,L., Moreau,E., Artana,G. and Touchard,G. "Influence of a DC corona discharge on the airflow along an inclined flat plate". 2001.J. Electrostat. 50-51. 300-6

Likhanskii, A.V., Shneider M.N., Opaits D.F., Miles R.B., Macheret S.O. Limitations of the DBD effects on the external flow. 48th AIAA Aerospace Sciences Meeting Including the New Horizons Forum and Aerospace Exposition 4 - 7 January 2010, Orlando, Florida AIAA 2010-470.

Loiseau,J.F., Batina,J., Noel,F., and Peyrous,R. "Hydrodynamical simulation of the electric wind generated by successive streamers in a point-to-plane reactor". 2002. J. Phys.D: Appl. Phys. 35 1020-31

Lopera,J., and Ng,T.T., Corke,T.C. "Aerodynamic Control of 1303 UAV Using Windward Surface Plasma Actuators on a Separation Ramp". 45th AIAA Aerospace Sciences Meeting and Exhibit 8 - 11 January 2007, Reno, Nevada, AIAA 2007-636

Macheret SO, Shneider MN, and Miles RB. 2001a Potential performance of supersonic MHD power generators. AIAA-2001-0795.

Macheret,S.O., Ionikh,Y.Z., Chernysheva,N.V., Yalin,A.P., Martinelli,L., and Miles,R.B. "Shock Wave Propagation and Dispersion in Glow Discharge Plasmas," Physics of Fluids, Vol. 13, No. 9, September 2001, pp. 2693-2705.

Mark H. J.Aeron.Shi. 1957. V.24. N 4. P. 304. 
Maslov A.A., Sidorenko A.A., Zanin B.Yu., Postnikov B.V., Budovsky A.D., Starikovskii A.Yu., Roupassov D.V., Zavialov I.N., Malmuth N.D. Pulsed Discharge Actuators for Rectangular Wing Separation Control 45th AIAA Aerospace Sciences Meeting and Exhibit 8 - 11 Jan 2007 Grand Sierra Resort Hotel Reno, Nevada. Paper AIAA2007-0941

Meyer,R., Palm,P., Ploenjes,E., Rich,J.W. and Adamovich,I.V. "Nonequilibrium Radio Frequency Discharge Plasma Effect on a Conical Shock Wave: M=2.5 Flow", AIAA Journal, vol. 41, No. 5, 2003, pp. 465-469

Mhitaryan A.M., Labinov S.D., Fridland V.Ya. Electro-hydrodynamic method of boundary layer control // in paper collection "Some problems of aerodynamics and electrohydrodynamics", vol.1, Kiev's Institute of Civil Aviation Engineers, Kiev, 1964.

Mhitaryan A.M., Maksimov V.S., Flidland V.Ya., Labinov S.D. Technology of boundary layer investigation with a new type work panel. IFZh. Volume 4, 1961.

Miles RB, Macheret SO, Martinelli L, Murray R, Shneider M, Ionikh Y.Z, Kline J, and Fox J. 2001 Plasma control of shock waves in aerodynamics and sonic boom mitigation. AIAA-2001-3062.

Miles R.B., Plasma flow control, fundamentals, modeling, and applications. Lecture Series Notes for Von Karman Institute Lectures. 2011.

Moreau,E. "Airflow control by non-thermal plasma actuators". J. Phys. D: Appl. Phys. 40 (2007) 605-636

Nemchinov I.V., Artemiev V.I., Bergelson V.I. New gasdynamic structures development by gas density change in thing longitudinal channels ahead of shock wave front. Mathematical Modeling. 1989. V. 1. N 8. PP. 1-11.

Nikipelov A., Nudnova M., Roupassov D., Starikovskiy A. Acoustic Noise and Flow Separation Control by Plasma Actuator. AIAA-2009-695. 47th AIAA Aerospace Sciences Meeting including The New Horizons Forum and Aerospace Exposition, Orlando, Florida, Jan. 5-8, 2009

Opaits,D.F., Roupassov,D.V., Starikovskaia,S.M., Starikovskii,A.Yu. "Shock Wave Interaction With Nonequilibrium Plasma of Gas Discharge". 42nd AIAA Aerospace Sciences Meeting and Exhibit, Reno, Nevada, 2004.

Opaits D.F., Roupassov D.V., Starikovskaia S.M., Starikovskii A.Yu., I.N.Zavialov, S.G.Saddoughi Plasma Control of Boundary Layer Using Low-Temperature Nonequilibrium Plasma of Gas Discharge. 43-rd AIAA Aerospace Sciences Meeting and Exhibit, 2005. Reno, Nevada, USA, paper AIAA 2005-1180, 2005.

Patel,M.P., Ng,T.T., Vasudevan,S., Corke,T.C., Post,M.L., McLaughlin,T.E., Suchomel,C.F. "Scaling Effects of an Aerodynamic Plasma Actuator". 45th AIAA Aerospace Sciences Meeting and Exhibit 8 - 11 January 2007, Reno, Nevada AIAA 2007-635

Popov N.A. Plasma Physics Reports. 27, 866 (2001).

Post,M.L., Greenwade,S.L., and Yan,M.H., Corke,T.C., Patel,M.P. "Effects of an Aerodynamic Plasma Actuator on an HSNLF Airfoil". 45th AIAA Aerospace Sciences Meeting and Exhibit. 8 - 11 January 2007, Reno, Nevada. AIAA 2007-638

Raizer,Yu.P. "Gas Discharge Physics". Berlin, Heidelberg, New York. Springer-Verlag. 1991.

Rickard,M., Dunn-Rankin,D., Weinberg,F., and Carleton,F. "Maximizing ion-driven gas flows". 2006. J. Electrostat. 64 368-76

Rios M., Nudnova M., Kindusheva S., Aleksahdrov N., Starikovskiy A. Fast Nonequilibrium Plasma Thermalization in $\mathrm{N}_{2}-\mathrm{O}_{2}$ Mixtures for Different Pulse Polarities. 49th AIAA Aerospace Sciences Meeting. Orlando, Florida. Jan 2011. Paper AIAA-2011-1275. 
Roth J.R. Aerodynamic flow acceleration using paraelectric and peristaltic electrohydrodynamic effects of a one atmosphere uniform glow discharge plasma. Phys. Plasmas 10: 2117-26, 2003.

Roth,J.R., Sherman,D.M. and Wilkinson,S.P. "Boundary layer flow control with a one atmosphere uniform glow discharge surface plasma" 1998.AIAA Meeting (Reno, USA, January 1998) paper N98-0328

Roth,J.R. "Electrohydrodynamically induced airflow in a one atmosphere uniform glow discharge surface plasma". 1998.25th IEEE Int. Conf. Plasma Science (Raleigh, USA)

Roth,J.R., Sherman,D.M. and Wilkinson,S.P. "Electrohydrodynamic flow control with a glow discharge surface plasma". 2000. AIAA J. 38 1172-9

Roth,J.R., and Dai,X. "Optimization of the Aerodynamic Plasma Actuator as an Electrohydrodynamic (EHD) Electrical Device". 44th AIAA Aerospace Sciences Meeting and Exhibit 9 - 12 January 2006, Reno, Nevada

Roupassov,D.V., Zavyalov,I.N., Starikovskii,A.Yu., Saddoughi,S.G. "Boundary Layer Separation Plasma Control Using Low-Temperature Non-Equilibrium Plasma of Gas Discharge". 44th AIAA Aerospace Sciences Meeting and Exhibit, 9 - 12 January 2006, Reno, Nevada. AIAA 2006-373

Roupassov,D.V., Zavyalov,I.N., Starikovskii,A.Yu., Saddoughi,S.G. "Boundary Layer Separation Control by Nanosecond Plasma Actuators". AIAA 2007-4530. Joint Prorulsion Conference, 2007, Miami, Florida.

Roupassov,D., Nudnova,M., Nikipelov,A., Starikovskii,A. "Sliding DBD for Airflow Control: Structure and Dynamics". 46th AIAA Aerospace Sciences Meeting and Exhibit 7 - 10 Jan 2008 Grand Sierra Resort Hotel Reno, Nevada. Paper AIAA-20081367.

Roupassov D.V., Starikovskii A.Y., Development of Nanosecond Surface Discharge in "Actuator" Geometry. IEEE Transactions on Plasma Science Volume 36, Issue 4, Part 1, Aug. 2008 Page(s):1312 - 1313

Roupassov D., Nikipelov A., Nudnova M., Starikovskii A., Flow Separation Control by Plasma Actuator with Nanosecond Pulsed-Periodic Discharge. AIAA Journal (2009) 0001-1452 vol.47 no.1 (168-185)

Samimy M, Kim J-H, Kastner J, Adamovich I, and Utkin Y. 2007 Active control of highspeed, and high-Reynolds number jets using plasma actuators. Journal of Fluid Mechanics 578: 305-330, 2007.

Shang,J.S. "Plasma injection for hypersonic blunt body drag reduction". 2002.AIAA J. 40(6), 1178-1186.

Shneider M.N., Macheret S.O., and Miles R.B. Analysis of Magnetohydrodynamic Control of Scramjet Inlets. AIAA Journal. Vol. 42, No. 11, November 2004

Sidorenko,A.A., Zanin,B.Yu., Postnikov,B.V., Budovsky,A.D., Starikovskii,A.Yu., Roupassov,D.V., Zavialov,I.N., Malmuth,N.D., Smereczniak,P., Silkey,J.S. "Pulsed Discharge Actuators for Rectangular Wing Separation Control". 45th AIAA Aerospace Sciences Meeting and Exhibit 8 - 11 January 2007, Reno, Nevada. AIAA 2007-941

Sigmond,R.S., and Lagstadt,I.H. "Mass and species transport in corona discharges". 1993. High Temp. Chem. Proces. 2 221-9 71 417-36

Starikovskaia,S.M., Anikin,N.B., Pancheshnyi,S.V., Starikovskii,A.Yu. "Time resolved emission spectroscopy and its applications to study of pulsed nanosecond highvoltage discharge". 2002. Proceedings of SPIE, V. 4460, pp. 63-73.

Starikovskii A.Yu. Plasma supported combustion, Proceedings of the Combustion Institute, 30, 2405-2417 (2005). 
Starikovskii A., Anikin N., Kosarev I., Mintoussov E., Nudnova M., Rakitin A., Roupassov D., Starikovskaia S., Zhukov V., Nanosecond-Pulsed Discharges for PlasmaAssisted Combustion and Aerodynamics. Journal of Propulsion and Power 2008. 0748-4658 vol.24 no.6 (1182-1197)

Starikovskii A.Yu., Nikipelov A.A., Nudnova M.M. and Roupassov D.V. SDBD plasma actuator with nanosecond pulse-periodic discharge Plasma Sources Sci. Technol. 18 No 3 (August 2009) 034015 (17pp)

Thomas F.O., Corke T.C., Iqbal M., Kozlov A., and Schatzman D. Optimization of Dielectric Barrier Discharge Plasma Actuators for Active Aerodynamic Flow Control AIAA Journal Vol. 47, No. 9, September 2009

Unfer T. and Boeuf J.P. Modeling of a nanosecond discharge actuator", J. Phys. D: Appl. Phys. 42194017 (2009)

Van Wie D. Paper presented at the RTO AVT Lecture Series on -Critical Technologies for Hypersonic Vehicle Development, at the von Kármán Institute, Rhode-St-Genèse, Belgium, 10- 14 May, 2004, and published in RTO-EN-AVT-116.

Van Wie D. M., Risha D. J., and Suchomel C. F., "Research Issues Resulting from an Assessment of Technologies for Future Hypersonic Aerospace Systems, AIAA2004-1257, January 2004.

Velkoff,H. and Ketchman,J. "Effect of an electrostatic field on boundary layer transition" 1968.AIAA J. 16 1381-3

Visbal M.R., Gaitonde D.V. Control of Vortical Flows Using Simulated Plasma Actuators. 44th AIAA Aerospace Sciences Meeting and Exhibit 9 - 12 January 2006, Reno, Nevada AIAA 2006-505.

Yabe, A., Mori, Y., Hijikata, K. "EHD study of the corona wind between wire and plate electrodes",1978, AIAA J., Vol. 16 pp.340-5.

Zhukov V.P., Kindusheva S.V., Kirpichnikov A.A., Kosarev I.N., Starikovskaia S.M., Starikovskii A.Yu. Plasma Production for MHD Power Generation by Nanosecond Discharge. 44th AIAA Aerospace Sciences Meeting and Exhibit 9 - 12 Jan 2006. Reno Hilton. Reno, Nevada. Paper AIAA-2006-1370

Zouzou,N., Moreau,E., and Touchard,G. "Precipitation electrostatique dans une configuration pointe-plaque". 2006. J.Electrostat. 64 537-42 


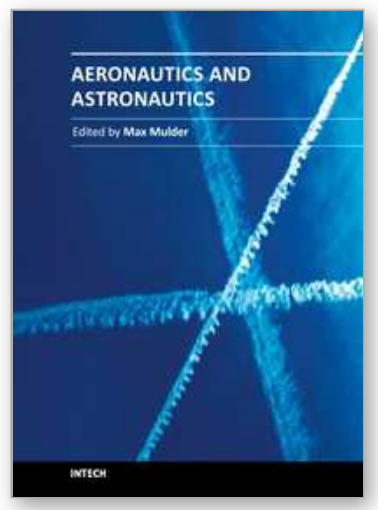

\author{
Aeronautics and Astronautics \\ Edited by Prof. Max Mulder
}

ISBN 978-953-307-473-3

Hard cover, 610 pages

Publisher InTech

Published online 12, September, 2011

Published in print edition September, 2011

In its first centennial, aerospace has matured from a pioneering activity to an indispensable enabler of our daily life activities. In the next twenty to thirty years, aerospace will face a tremendous challenge - the development of flying objects that do not depend on fossil fuels. The twenty-three chapters in this book capture some of the new technologies and methods that are currently being developed to enable sustainable air transport and space flight. It clearly illustrates the multi-disciplinary character of aerospace engineering, and the fact that the challenges of air transportation and space missions continue to call for the most innovative solutions and daring concepts.

\title{
How to reference
}

In order to correctly reference this scholarly work, feel free to copy and paste the following:

Andrey Starikovskiy and Nickolay Aleksandrov (2011). Nonequilibrium Plasma Aerodynamics, Aeronautics and Astronautics, Prof. Max Mulder (Ed.), ISBN: 978-953-307-473-3, InTech, Available from:

http://www.intechopen.com/books/aeronautics-and-astronautics/nonequilibrium-plasma-aerodynamics

\section{INTECH}

open science | open minds

\section{InTech Europe}

University Campus STeP Ri

Slavka Krautzeka 83/A

51000 Rijeka, Croatia

Phone: +385 (51) 770447

Fax: +385 (51) 686166

www.intechopen.com

\section{InTech China}

Unit 405, Office Block, Hotel Equatorial Shanghai

No.65, Yan An Road (West), Shanghai, 200040, China

中国上海市延安西路 65 号上海国际贵都大饭店办公楼 405 单元

Phone: +86-21-62489820

Fax: +86-21-62489821 
(C) 2011 The Author(s). Licensee IntechOpen. This chapter is distributed under the terms of the Creative Commons Attribution-NonCommercialShareAlike-3.0 License, which permits use, distribution and reproduction for non-commercial purposes, provided the original is properly cited and derivative works building on this content are distributed under the same license. 